Guilt and Self-Forgiveness for Smoking:

Emotional Arousal and Motivation for Smoking Cessation

\title{
Andrea Thompson
}

Thesis submitted to

The faculty of Graduate Studies and Research

In partial fulfillment of the requirements

For the degree of Master of Arts

\author{
Department of Psychology \\ Carleton University \\ Ottawa, Ontario
}

(c) September 2006

This research was supported by the

Social Sciences and Humanities Research Council of Canada 


$\begin{array}{ll}\begin{array}{l}\text { Library and } \\ \text { Archives Canada }\end{array} & \begin{array}{l}\text { Bibliothèque et } \\ \text { Archives Canada }\end{array} \\ \begin{array}{l}\text { Published Heritage } \\ \text { Branch }\end{array} & \begin{array}{l}\text { Direction du } \\ \text { Patrimoine de l'édition }\end{array} \\ \begin{array}{l}\text { 395 Wellington Street } \\ \text { Ottawa ON K1A ON4 }\end{array} & \begin{array}{l}\text { 395, rue Wellington } \\ \text { Ottawa ON K1A ON4 } \\ \text { Canada }\end{array}\end{array}$

Your file Votre référence ISBN: 978-0-494-18303-8 Our file Notre référence ISBN: 978-0-494-18303-8

NOTICE:

The author has granted a nonexclusive license allowing Library and Archives Canada to reproduce, publish, archive, preserve, conserve, communicate to the public by telecommunication or on the Internet, loan, distribute and sell theses worldwide, for commercial or noncommercial purposes, in microform, paper, electronic and/or any other formats.

The author retains copyright ownership and moral rights in this thesis. Neither the thesis nor substantial extracts from it may be printed or otherwise reproduced without the author's permission.
AVIS:

L'auteur a accordé une licence non exclusive permettant à la Bibliothèque et Archives Canada de reproduire, publier, archiver, sauvegarder, conserver, transmettre au public par télécommunication ou par l'Internet, prêter, distribuer et vendre des thèses partout dans le monde, à des fins commerciales ou autres, sur support microforme, papier, électronique et/ou autres formats.

L'auteur conserve la propriété du droit d'auteur et des droits moraux qui protège cette thèse. $\mathrm{Ni}$ la thèse ni des extraits substantiels de celle-ci ne doivent être imprimés ou autrement reproduits sans son autorisation.
In compliance with the Canadian

Privacy Act some supporting forms may have been removed from this thesis.

While these forms may be included in the document page count, their removal does not represent any loss of content from the thesis.
Conformément à la loi canadienne sur la protection de la vie privée, quelques formulaires secondaires ont été enlevés de cette thèse.

Bien que ces formulaires aient inclus dans la pagination, il n'y aura aucun contenu manquant.

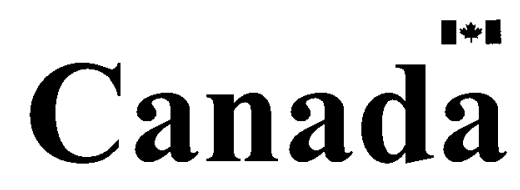




\begin{abstract}
The transtheoretical model of behavioural change has identified three distinct stages (precontemplation, contemplation, and preparation) of increasing motivation smokers go through before abstinence from smoking is achieved. However, the factors that differentiate one stage from the next remain unclear. The present study sought to explore the influence of emotional factors on the desire for and attainment of smoking cessation through application of Brehm's model of emotional intensity. Specifically, the roles of guilt and self-forgiveness in the promotion and inhibition of smoking cessation were assessed. In a survey of 186 smokers, higher levels of guilt among were associated with being more motivated to quit for women, while higher levels of self-forgiveness were predictive of being less motivated for both gender. Furthermore, guilt and selfforgiveness were found to mediate the relationship between stage of change and recognition of the negative effects of smoking.
\end{abstract}




\section{Acknowledgements}

There are a number of people that were important to the success of this thesis.

First and foremost, I would like to extend my appreciation to my committee members for their helpful comments and suggestions, as well as for their constant encouragement and support. I am especially indebted to my supervisor, Michael Wohl. This project would not have been as interesting or enjoyable as it was without his thoughtful insights, constant dedication, and disarming sense of humour.

I would also like to thank Celina Boulé-Perroni, who assisted greatly in the recruitment of participants, collection of data and countless other tasks. It was wonderful to have someone to work on this project with, and it was even more wonderful to work with someone as bright and energetic as Celina.

Finally, I would like to thank my husband, Peter. I am eternally grateful for his uncanny ability to be, at once, challenging and supportive. The unconditional love and support he has given me has meant the world to me and has made completing this project so much more meaningful. 


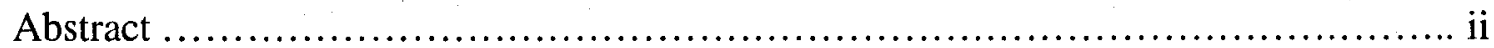

Acknowledgements .....................................................

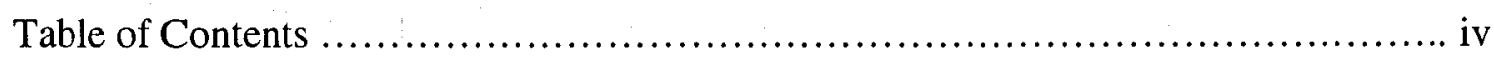

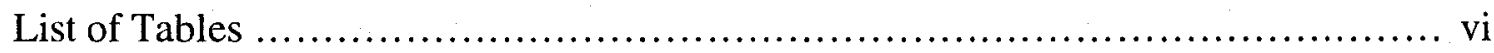

List of Appendices........................................................ vii

Chapter 1 ..................................................................

Introduction..................................................................

Motivation for Smoking Cessation.......................................... 2

The Transtheoretical Model of Behavioural Change................................ 4

The Experience of Guilt: An Emotional Response that Facilitates Behavioural Change..10

Self-Forgiveness: Helpful or Harmful in the Process of Behavioural Change? ........... 14

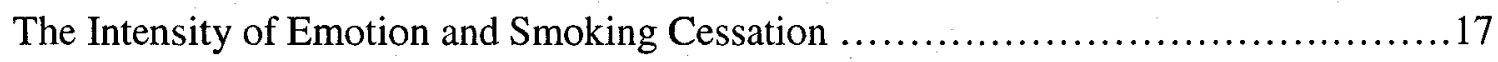

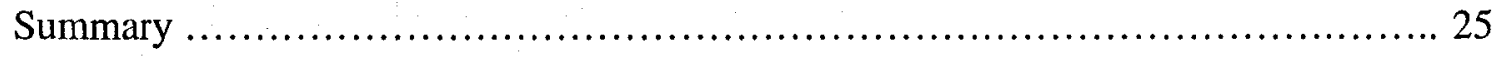

Chapter 2 .................................................................. 26

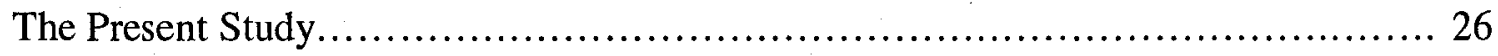

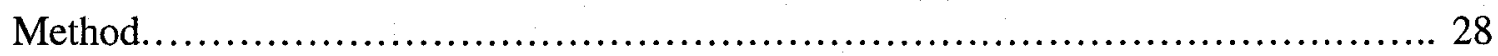

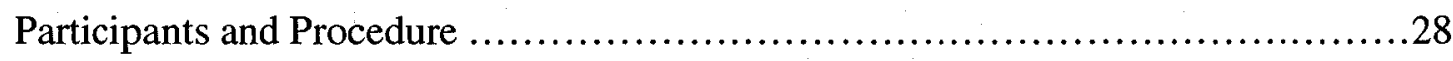

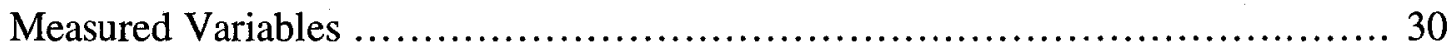


Results

Smoker Demographics.

Perception of Smoking as a Transgression

Gender Differences 38

Guilt, Self-Forgiveness and Perceived Quitting Difficulty. .46

Stage of Change, Guilt, Self-Forgiveness and Perceived Quit Difficulty........ 48

Mediational Models. 52

Factors Associated with Behavioural Change. 57

Chapter 4 61

Discussion 61

Limitations 69

Future Research 72

Concluding Remarks 73

References 75 


\section{List of Tables}

Table 1: Correlations among decisional balance subscales ....................................... 34

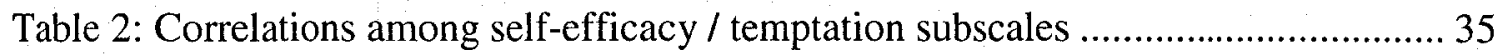

Table 3: Correlations among process of change subscales ........................................ 36

Table 4: Perceptions of smoking as a transgression .................................................... 38

Table 5: Descriptive Statistics (Means, SDs) as a function of gender........................... 39

Table 6: Descriptive Statistics (Means, SDs) for men and women as a function of time 1

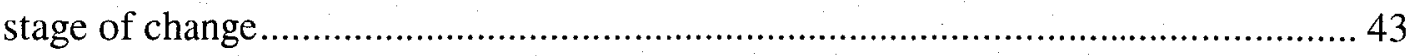

Table 7: Regression analysis predicting guilt from self-forgiveness and perceived quitting

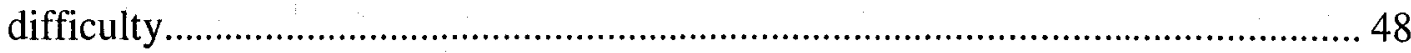

Table 8: Results of multinomial logistic regressions with guilt, self-forgiveness and difficulty predicting stage of change conducted for women and men separately.... 51

Table 9: Concordance rates for observed and predicted stage of change for women and

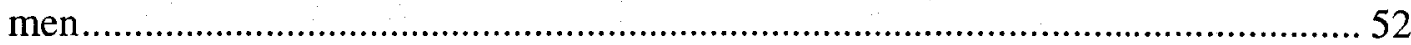

Table 10: Results of mediational analyses for women with guilt as the mediator,........... 55

Table 11: Results of mediational analyses for women with self-forgiveness as the

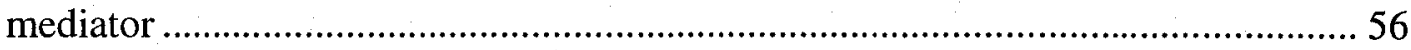

Table 12: Results of mediational analyses for men with self-forgiveness as the mediator

Table 13: Abstinence predicted by guilt, self-forgiveness, and difficulty 59 


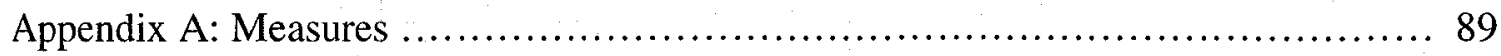

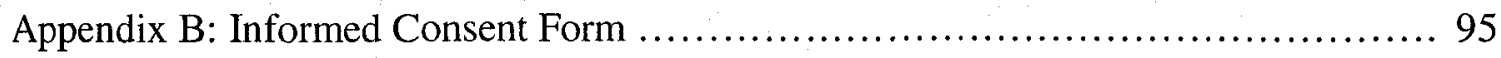

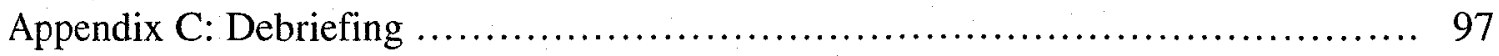

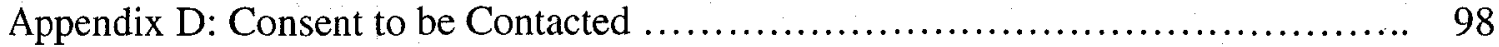

Appendix E: Preliminary Analyses ........................................... 99 
Guilt and Self-Forgiveness for Smoking:

Emotional Arousal and Motivation for Smoking Cessation

\section{Chapter 1}

\section{Introduction}

In recent decades smokers and non-smokers alike have become increasingly aware of the negative effects of cigarette smoking (DeBernardo, et al., 1998). Past research has linked tobacco smoking to a host of health problems including cancer, heart disease and premature death (Brownson, Eriksen, Davis \& Warner, 1997; Ellison, Morrison, de Groh, \& Villenuve, 2000). Recently, more attention has been given to the effects of environmental tobacco smoke (ETS) on the health of non-smokers. Exposure to ETS has been linked to serious health problems including lung cancer, heart disease, bronchitis and pneumonia (Brownson, et al., 1997). However, despite having knowledge of these negative consequences, approximately $18 \%$ of Canadians are daily smokers, and the smoking rate for young people aged 20 to 24 is even higher, at 23\% (Health Canada, 2003). Considering that almost half of current and former smokers initiated smoking during their young adulthood (Statistics Canada, 2003), young people who smoke are at increased risk for becoming life-long smokers (Alvarado \& Breslau, 2005). Yet, although young smokers have been inundated with anti-smoking education and media campaigns throughout their entire lives, less than half of young smokers are interested in quitting (Health Canada, 2003). This lack of interest in quitting emphasises the need for a better understanding how smoking behaviour change is facilitated and inhibited among current young smokers. The purpose of the current study was to increase knowledge in this area by demonstrating how emotions are important to the motivation of smoking cessation. 
Past explorations of the factors that promote smoking cessation in young adults have focused on the environmental factors linked to successful quit attempts. For example, an Australian study of adolescent and adult smokers found that factors such as household restrictions on smoking and having friends who do not smoke were associated with an increased likelihood of cessation (Siahpush, Borland, \& Scollo, 2003). Individual factors believed to influence cessation include knowledge of the adverse health effects of smoking (Hyland, Bauer, Giovino, Steger, \& Cummings, 2004; Murphy-Hoefer, Alder, \& Higbee, 2004; Siahpush, et al., 2003) and severity of nicotine dependence (Hyland et al., 2004). Lacking in the current smoking literature is an understanding of the underlying motivations that lead a smoker to quit. For example, although Hyland and colleagues (2005) have demonstrated that some smokers spontaneously reduce the number of cigarettes smoked, they were unable to determine what led these people to reduce their smoking consumption when others did not. This lack of understanding limits practitioners' ability to effectively promote quitting behaviour. The present study sought to address this issue by examining the potential of emotional factors to promote efforts towards smoking cessation.

\section{Motivation for Smoking Cessation}

While the value of previous research on smoking cessation is not to be dismissed (e.g., Hyland, et al, 2004; Murphy-Hoefer, Alder, \& Higbee, 2004; Siahpush, et al., 2003), this research has targeted only those who are already motivated towards the achievement of smoking abstinence. This focus excludes many current young smokers who are not yet interested in quitting from analysis and therefore fails to provide a complete understanding of barriers to smoking cessation that may be present. A more 
parsimonious understanding of smoking cessation may be achieved through the identification of factors that influence peoples' willingness to quit smoking. The present study sought to increase understanding in this area by examining specific emotional factors that may facilitate motivation for smoking cessation in young adults. Specifically, the present study explored the effect of the emotions of guilt and self-forgiveness experienced in reaction to personal smoking behaviour on motivation for smoking cessation. In doing so, the current study aimed to extend knowledge in this area by presenting a novel way of looking at motivation for smoking cessation.

Interestingly, the role of specific emotions as a motivator for smoking cessation has largely been ignored (for expectations see Hajek \& Belcher, 1991 and Turner \& Mermelstein, 2005), yet several studies have demonstrated the importance of emotions in the stimulation of other addictive behaviours. For example, individuals with lesions in areas of the brain associated with emotion (e.g., the amygdala) have been found to be less responsive to wins and losses when making investment decisions than individuals with lesions in areas of the brain not related to emotion (Shiv, Loewenstein, Bechara, Damasio, \& Damasio, 2005). Although Meyer and Waller (1999) have found that women who were exposed to a negative emotional cue of abandonment (intended to promote feelings of loneliness) ate more than women who were exposed to a neutral cue (intended to produce no emotion), a more positive emotional cue (intended to promote feelings of happiness, ) or an appetitive cue (intended to promote feelings of hunger). Furthermore, this study found that women with unhealthy attitudes towards eating are more likely to overeat after receiving a hostile emotional cue intended to produce anger. This suggests that the arousal of certain emotions may also lead to increases of other forms of 
consumption, such as cigarette smoking. The present study attempted to extend research in this area by exploring how the emotional arousal of guilt and self-forgiveness influences motivation for smoking cessation.

Before exploring how the emotions of guilt and self-forgiveness may impact motivation for smoking cessation, it is important to understand how variations in the motivation for smoking cessation have been traditionally viewed. Any effort towards behavioural change must first be preceded by the desire and motivation for change. Thus, the desire to become smoking abstinent is required before a quit attempt can be made. One theory that has emphasized and identified different levels of motivation for change is the Transtheoretical Model (TTM; Prochaska \& DiClemente, 1983, 1986). Although this theory has been used to assess change for a variety of behaviours, from exercise adoption to substance abuse, it has been primarily used as tool in the assessment motivation for smoking cessation (Rosen, 2000). Thus, it will also be used here to elucidate how guilt and self-forgiveness influence differences in motivation for smoking cessation.

\section{The Transtheoretical Model of Behavioural Change}

The TTM was formed in an attempt to consolidate several components believed to be important to the process of behavioural change into a unified theory. Of central importance to the TTM is the notion that the modification of any long-standing behaviour is marked by discrete stages of increasing motivation for change that are based on temporally placed intentions towards change (e.g., planning to quit smoking within the month) and previous attempts at changing (i.e., number of attempts at quitting in the last year). The TTM model currently identifies five stages (DiClemente, et al., 1991), namely, precontemplation, where behavioural change is not desired in the next 6 months; 
contemplation, where change is desired within the next six months but not within the next 30 days, or where change is desired within the next 30 days, but no previous attempt at changing has been made; preparation, where change is desired within the next 30 days and there has been a previous attempt made at changing in the last year; action, where change has been made, but not yet been maintained for 12 consecutive months; and maintenance, where change has been successfully achieved for 12 consecutive months. Thus, the staging model discretely classifies smokers in terms of their current level of motivation to for change.

The utility of this classification system has been investigated in several studies which have consistently found that the staging algorithm is an effective predictor of previous quit attempts (Pearlman, Wernicke, Thorndike \& Haage, 2004) and future smoking abstinence (DiClemente, et al., 1991; Fava, Velicer \& Prochaska, 1995; Prochaska, Velicer, Prochaska, \& Johnson, 2004; Segan, Borland \& Greenwood, 2004). That is, smokers identified as in the preparation stages are more likely to be abstinent in the future than smokers in the precontemplation or contemplation stages. This suggests that classifying smokers according to the TTM stages of change is an effective method of identifying those most likely to quit. Although individuals are expected to pass through each stage, in order, as they approach the achievement of long-term change, the pattern of transition is not expected to be linear. Rather, the change process is expected to be marked by several cycles of progression and regression between the action stage and other previous stages before change at the maintenance stage is achieved.

Research using the TTM has also attempted to describe how these transitions are facilitated through the use of several psychological and behavioural constructs that are 
believed to be indicative of each stage (Prochaska \& DiClemente, 1983). These constructs include the acknowledgement of the advantages and disadvantages of maintaining the current behaviour (i.e., the pros and cons of the current behaviour), the perception of personal ability to change (i.e., self-efficacy), as well as specific behaviours and cognitions, jointly referred to as the processes of change, believed to be associated with the change process (Prochaska, Velicer, DiClemente \& Fava, 1988). Each of these behaviours and cognitions fall into one of the four broader categories of Experiential, Behavioural, Reevaluation, and Management. The Experiential category represents increased attention to information about negative societal views of smoking (consciousness raising) and the negative effects smoking has on the environment (environmental). The Behavioural category reflects efforts towards seeking social support (helping relationships), receiving rewards for not smoking (reinforcement), overcoming temptations (counter conditioning) and self-encouragement (self-liberation).

Reevaluation reflects emotional responses to smoking, including having negative thoughts associated with smoking (self-reevaluation), awareness of changing social views (social liberation), and emotional reactions to the negative effects of smoking (dramatic relief), while Management refers to the removal of smoking cues (stimulus control).

Empirical investigations of current and former smokers at each stage of change have shown that the transition from a pre-active stage (e.g., contemplation) to an active stage (e.g., action) is marked by shifts in the levels of these constructs. Specifically, Schumann and colleagues (2005) have found that the decreases in the perception of the advantages of smoking (i.e., smoking pros) were accompanied by increases in the perceived advantages of quitting (i.e., smoking cons). This study also found that 
improved self-efficacy regarding ability to quit and overcome temptations was indicative of the transition from a non-abstinent stage to an abstinent stage.

Evaluations of the processes of change construct have yielded less consistent results (Herzog, Abrams, Emmons, Linnan \& Shadel, 1999; Pearlman, et al., 2004; Segan, et al., 2004). Investigations of the processes of change have consistently shown that individuals in the pre-active stages are more likely to make use of the experiential processes, whereas individuals in the active stages are more likely to make use of the behavioural processes (Prochaska, Velicer, DiClemente, \& Fava, 1988; Rosen, 2000; Segan, et al., 2004). However, the predictive utility of the TTM has also been challenged by studies which found that differences in the TTM constructs are not associated with movement between the pre-active stages (Herzog, et al., 1999; Pearlman, et al., 2004; Segan, et al., 2004). This has severely limited the usefulness of the TTM in describing how individuals increase in their motivation for smoking cessation. Considering that the progression and regression between stages is a central concept of the TTM, a better understanding how motivation for smoking cessation is both promoted and inhibited is needed. Rather than abandon the theory all together, the present study sought to augment the TTM by exploring how the emotions of guilt and self-forgiveness are experienced in response to continued smoking behaviour. Specifically, these emotions will be assessed as possible predictors of movement between the pre-active stages.

Preliminary evidence of the importance of emotions in the desire for smoking cessation has come from studies that have investigated the reasons individuals give for wanting to change their smoking behaviour. For example, McKee and colleagues (2005) have found that when people think about changing their smoking behaviour they consider 
both the risks, such as weight gain and the occurrence of withdrawal symptoms, and the benefits, such as improved health and well-being. In their study of current smokers, they have found that increased awareness of the potential risks of quitting was associated with decreased motivation for quitting, while increased awareness of potential benefits of quitting was associated with increased motivation for quitting. Clearly, this demonstrates that smokers are concerned with not only the negative effects of their smoking, but also the positive effects gained from this behaviour. This finding has implications for the role of emotions in directing motivation, as different affectual experiences are likely to be associated with different perceptions of behaviour. Specifically, it would be expected that smokers who are more concerned with the positive effects of quitting (e.g., increased energy) would experience more negative affect towards the continuation of smoking than smokers who are more concerned with the positive effects of continuing to smoke (e.g., experience of pleasure from the nicotine). Thus, different affectual experiences are likely to accompany different perceptions of smoking behaviour and may therefore serve to promote or inhibit motivation for behaviour change.

Research, conducted by Curry and colleagues (Curry, Grothaus, \& McBride, 1997; Curry, Marlatt, Gordon \& Baer, 1988) has focused on differentiating specific reasons for achieving smoking cessation in terms of their relationship to the self. This research has shown that the most common reasons for wanting to quit smoking can stem from motivations that originate within the smoker (internal motivations) or originate from the smoker's environment (external motivations). Of the intrinsic motivations associated with a desire for cessation, health concerns (e.g., getting sick) and the achievement of self-control (e.g., overcoming addiction) were most often cited by current smokers as 
reasons for quitting. In terms of extrinsic motivations, the most often cited reasons for quitting included reinforcement goals (e.g., decreased financial costs) and social influences (e.g., pleasing parents). Heightened concern for one's health and increased self-control were positively associated with increased motivation for smoking cessation over time (Curry, et al., 1997). Likewise, individuals who list a higher number of intrinsic motivations relative to extrinsic motivations increase their likelihood of achieving abstinence (Curry, et al., 1997; Turner \& Mermelstein, 2004). Thus, intrinsic motivation is particularly influential in motivating smoking cessation.

It is proposed that emotions that motivate the self to take action will also be effective in this regard. For example, guilt has been shown to stimulate the self to change past behaviours (Tangney, Boone \& Dearing 2005). Thus, if a smoker feelings guilty about this behaviour, he or she may become motivated to quit. However, even when a high degree of intrinsic motivation is present, opposing motivations can keep actual cessation rates below $10 \%$ (Turner \& Mermelstein, 2004). For example, people are motivated to feel good about themselves and their actions (Miller \& Ross, 1975). As such, people may be especially willing to let go of the negative feelings (i.e., forgiven the self) that results from perceived inappropriate behaviours committed by the self. Thus, although some emotions may inhibit smoking behaviours other emotional factors may result in smoking maintenance. Following this, the present study will examine the two opposing emotional forces of guilt and self-forgiveness that are likely to occur as a result of continued smoking behaviour. Furthermore, the effect of these emotions on motivation for smoking cessation was investigated to determine if smoking cessation is promoted and inhibited by emotional forces. 
The Experience of Guilt: An Emotional Response that Facilitates Behavioural Change

Guilt has been conceptualized as a self-conscious emotion that produces negative affect in response to a wrong-doing that is intimately connected to the social world (Barrett, 1995; Tangney et al., 2005). That is, the experience of guilt is likely to occur when something is done that violates a social standard. Considering that the common view of smoking in contemporary society is increasingly negative (Kim \& Shanahan, 2003), smoking can be said to violate social standards of behaviour. Recent evidence has shown that this negative view of smoking may result in the stigmatization of those who continue to smoke (Gilbert, Hannan \& Lowe 1998). It is, therefore, to be expected that contemporary smokers would hold a more negative view of their own smoking behaviour, leading them to experience negative emotions, such as guilt.

Guilt is not the only emotion associated with the commission of transgressions. The emotions of regret and shame are closely tied to guilt (Gilovich and Medvec, 1995; Tangney \& Dearing, 2002) and may also result in the experience of negative affect in response to continued smoking behaviour. As such, it is likely that smokers who view their continued smoking behaviour as a transgression are likely to experience varying levels of regret and shame along with guilt. A recent study conducted by Berndsen and colleagues (2004) found regret to be more indicative of intrapersonal harms (i.e., transgressions committed against the self), although guilt is more indicative of interpersonal harms (i.e., transgressions against others). This implies that feelings of regret may be the more likely emotional response to continued smoking behaviour. This study also found that feelings of guilt for an intrapersonal harm were increased when the outcomes of the transgression have a significant impact on interpersonal relationships. As 
noted earlier, the effects of environmental tobacco smoke have been given increased attention, putting the interpersonal effects of smoking into focus. Additionally, reasons for quitting often include interpersonal aspects, such as wanting to please parents or friends (Curry, Wagner \& Grothaus, 1990; McKee, 2005). This implies that smoking behaviour is largely viewed as having interpersonal consequences, which, according to Berndsen and colleagues (2004) would increase feelings of guilt. Therefore, in terms of smoking cessation, guilt is the emotion that is most likely to be associated with motivation for behavioural change.

Guilt has also been closely tied to the similar emotion of shame. Although these emotions are commonly used interchangeably to describe the same experience, researchers interested in these constructs have often made the distinction that guilt is focused on the wrongfulness of the act, whereas shame is more focused on the wrongfulness of the person (Barrett, 1995; Lewis, 1992; Tangney \& Dearing, 2002). That is, guilt is experienced in response to a negative evaluation of a specific behaviour, but shame is experienced in response to a negative evaluation of the self; individuals feel guilty for committing the transgression and feel shame for being the type of person who would commit the transgression. As such, guilt is believed to stimulate action and a sense of moral obligation to make amends, whereas shame is believed to arouse feeling of helplessness and a desire to hide from the view of others (Tangney et al., 2005). Therefore, it is expected that guilt would stimulate efforts to change problem behaviours, while shame would not.

The view that guilt is adaptive, while shame is maladaptive, has received support from Leith and Baumeister (1998), who have shown that individuals who experience 
more guilt tend to be more considerate of the perspective of others, whereas individuals who experienced more shame tend to have more personal distress. Furthermore, the perspective enhancing effect of guilt was also found to be responsible for improved relationships, whereas shame was responsible for poorer relationships. In addition, an investigation of the associations of trait-guilt and trait-shame to both adaptive and maladaptive perfectionism has found that although guilt was associated with more negative forms of perfectionism (i.e., striving for unrealistic goals), this effect was eliminated when the effect of shame was removed (Fedewa, Burns \& Gomez, 2005). This research support the view held by Tangney and Dearing (2002) that guilt is only associated with decreased well-being when it is experienced in conjunction with shame. It is therefore likely that a "pure" shame-free guilt would be associated with increased motivation for positive change. For the purpose of this study, both guilt and shame for smoking will be measured individually, so that any possible effects of shame on the experience of guilt can be accounted for. It is therefore expected that when guilt is experienced for continued smoking behaviour in the absence of shame, well-being will be largely unaffected.

Although there is currently a paucity of research linking guilt to smoking behaviour, previous research has suggested that guilt is important to the desire for and achievement of smoking cessation. Research conducted by Hajek and Belcher (1991) has suggested that guilt may facilitate continued abstinence among former smokers. Their study found that abstinent smokers who dream of a smoking relapse typically experience feelings of guilt upon awakening. Furthermore, it was found that such dreams were predictive of future abstinence. This study provides further support for the notion that 
smokers experience guilt about their behaviour. Although this study only assessed guilt for smoking in a dream, it is possible that an actual relapse would produce a similar effect. Quiles, Kinnunen \& Bybee (2002) have also found that adolescents with higher dispositional guilt scores were less likely to use alcohol, marijuana and tobacco, suggesting that the tendency to experience guilt inhibits substance use. This provides valuable insights into the role of guilt and smoking behaviour, but it is somewhat limited in that only the tendency to experience guilt was assessed.

Indirect evidence that guilt specific to smoking behaviour is important in motivating smoking cessation is evidenced through a study conducted by Turner and Mermelstein (2005), which found that nearly $30 \%$ of adolescent smokers endorsed not wanting to be identified as a smoker as an important reason for quitting. Thus, adolescents who wanted to quit perceived their smoking as socially unattractive. As such, smoking was construed as violating a social standard that could induce feelings of guilt. Unfortunately, levels of guilt were not assessed in this study. The present study aims to extend research in this area by directly assessing guilt that is experienced, with regards to the specific transgression of smoking.

Although it appears that guilt for the specific behaviour of smoking could play a significant role in motivating desire for smoking cessation, it would be naïve to assume this relationship would hold in all instances and at all times. Other emotion-states may serve to counteract the experience of guilt, thus diminishing the need to make reparations that, in terms of smoking behaviour, can take the form of positive behavioural change. For instance, the presence of positive mood has found to negate the motivational effect of guilt on helping (Cunningham, Steinberg \& Grev, 1980). Considering the totality of 
emotional experience it is likely that the guilt one experiences for continued smoking behaviour would also be moderated by the presence or absence of other opposing emotions, such as self-forgiveness.

\section{Self-Forgiveness: Helpful or Harmful in the Process of Behavioural Change?}

Until relatively recently the empirical study of forgiveness was largely ignored by psychologists. In only the last ten years, a large body of research investigating the process of forgiveness has emerged (see Exline, et al., 2004 for a review). Research on forgiveness has tended to focus on the process of forgiving others (Enright and the Human Development study Group, 1996). Forgiveness, however, is a multidimensional emotion that can take several distinct forms (Worthington \& Scherer, 2004). Aside from the forgiveness of others, forgiveness can also be received from others and well as the granted to the self, although the latter form is traditionally neglected by researchers in favour of other-focused forgiveness. There is now a growing interest in the antecedents and consequences of self-forgiveness (e.g., Hall \& Fincham, 2005; Ingersoll-Dayton \& Krause, 2005).

Considering the initial emphasis on other-focussed forgiveness in the literature, it should not be surprising that the granting of forgiveness to the self have been drawn from previous work on granting forgiveness to others. Though both forms of forgiveness can be assumed to occur as reactions to a transgressor, unique processes are bound to emerge when the transgressor and the transgressed are one. A widely accepted action oriented conceptualization of other-focused forgiveness views this emotion as a process, in which destructive responses such as avoidance of and retaliation against the transgressor, are replaced with more constructive and loving behaviours (McCullough, Worthington, \& 
Rachal, 1997). This conceptualization is problematic for self-forgiveness, as avoidance of the transgressor (i.e., the self) is not possible. However, Hall and Fincham (2005) argue that when transgressions are committed against the self, forgiveness is accompanied by a decrease in motivation to avoid stimuli associated with the transgression committed against the self. If we accept that smoking is a transgression against the self, then we would expect that self-forgiveness granted for continued smoking behaviour would lead to decreased motivation to avoid those stimuli associated with smoking and its negative effects. Thus, smokers who grant themselves a high degree of self-forgiveness are less likely to avoid smoking related stimuli, such as the cigarettes, and therefore, more likely to continue their smoking behaviour.

As with guilt, self-forgiveness can be further conceptualized as representing either a general tendency or personality characteristic or a more state-dependent construct that occurs in response to specific transgressions. By and large, measures of self-forgiveness focus on the tendency to self-forgive (e.g., Mauger et al., 1992; Tangney, Fee, Reinsmith, Boone, \& Lee, 1999, in Tangney et al., 2005; Thompson et al., 2005). As a result, less emphasis has been given to state level self-forgiveness (for an exception see DeShea, Wohl, \& Wahkinney, 2005). Considering that the tendency to forgive others has been found to be only partially related to state forgiveness of others (Brown \& Phillips, 2005), we would expect that state-self-forgiveness would emerge as a unique construct, separable from a tendency to self-forgive. Of importance to the present study is the effect of granting oneself forgiveness for the specific transgression of smoking. As such, we will be concerned with levels of state self-forgiveness for a specific transgression (i.e., smoking) and not a person's tendency to forgive the self. 
Though granting forgiveness to others has typically been viewed as having a positive effect on individual well-being (Ross, et al., 2004), the effects of self-forgiveness are unclear. Forgiveness of others has been linked to increased agreeableness and decreases hostility (Ross et al., 2004). Additionally, people who forgive others have been shown to have less physiological stress responses (Witvliet, Ludwig, \& Vander Laan, 2001), and more satisfaction in close relationships (Thompson et al., 2005). Likewise, individuals with a tendency to self-forgive have been shown to experience less depressive, anxious and neurotic symptoms compared with those who tend to not forgive themselves (Maltby, Macaskill, \& Day, 2001; Ross, 2004). However, self-forgiveness may have an adverse affects when granted for the continuation of unhealthy behaviours, such as smoking. Tangney and colleagues (2005) have characterized the typical selfforgiver as self-centred, insensitive and narcissistic. They are viewed as lacking empathy and less likely to experience guilt. Although they exhibit little psychological distress, they have been found to exhibit less self-control (Tangney, Baumeister, \& Boone, 2004), which may lead them to engage in more harmful behaviours, such as smoking. Thus, granting oneself forgiveness for problem behaviours, such as smoking, may negatively effect well-being. Following this view, it proposed that self-forgive will have the opposite effect on desire for change as guilt, resulting in an inhibition of motivation for smoking cessation.

In sum, at least some level of guilt and self-forgiveness are likely to be experienced by smokers in response to their continued smoking behaviour. The present study seeks to explore how these emotions may influence progression between the stages of change outlined in the TTM. To better understand how this may be achieved, the 
present study will look to a theory of emotional intensity. In so doing, it will be made clear how motivation is achieved through the arousal of emotions.

\section{The Intensity of Emotion and Smoking Cessation}

The capacity of emotions to direct behaviour has been explored in depth by Brehm and colleagues (Brehm \& Brummett, 1998; Brehm, 1999), who have proposed a model of emotional intensity that emphasizes emotional arousal as the primary motivators of any action. According to this theory, emotions have the character of motivations states that are directed at the achievement of some outcome or outcome potential. Previous research has demonstrated that motivational intensity for any goal can be represented as a quadratic function (i.e., inverted ' $u$ ') of the difficulty of attaining the goal (see Brehm \& Self, 1989; Wright, 1996 for reviews). Specifically, it has been shown that when the difficulty of attaining a goal is unknown, motivation will be at its maximum potential. This potential is determined by the importance of the goal to the individual so that goals of highest importance will have the largest potential for motivation. As such, when the perception of difficulty is unknown, the intensity of motivation directly reflects the subjective value of the goal. When difficulty of achieving the goal is known, but very small, achievement of the goal will require little energy, and so motivation drops to a low level. As the level of difficulty of the goal increases, more energy is required. Thus, motivation for the goal will must also rise if the goal is to be achieved. Motivation will continue to rise in this manner until the level of difficulty of achieving the goal exceeds the energy available to attain it, at which point motivation is again reduced to a low level (e.g., Wright, Contrada, \& Patane, 1986). 
If emotions have the character of motivation states, then the level of emotional intensity should also fluctuate as a function of the difficulty of maintaining the emotion. With respect to emotions, this difficulty takes the form of anything that impedes the function of the emotion (Brehm, 1999; Silvia \& Brehm, 2001). As such, these impediments are referred to as deterrents. Thus, when deterrents to the current emotional state are absent or unknown, emotional intensity will be at some maximum potential that is determined by the subjective importance given to the function of the emotion. For example, the potential intensity of fear will be highest when the importance of escaping some threatening situation is greatest. When a deterrent is present and known, emotional intensity will drop to a low level. As the level of the deterrent rises, so too does emotional arousal, which leads to a greater experience of emotional intensity. The level of emotional intensity will continue to rise as the level of the deterrent rises, up to the point where the amount of emotional arousal needed to overcome the deterrents exceed the maximum potential intensity of the emotion.

Although the emotional intensity model seems counter-intuitive, direct experimentation using different emotions and deterrents has also been highly supportive. For example, Brehm and colleagues (1998) has found that the intensity of sadness can be manipulated by the introduction of a deterrent that took the form of an unexpected monetary reward. Participants in this study were first made to feel sad by reading a sad story. Afterwards, some of the participants received a $\$ 1, \$ 2$, or $\$ 3$ unexpected monetary reward for their participation. As expected, sadness was lowest when a low (\$1) or high (\$3) reward was received and highest when either no reward or a moderate reward (\$2) was received. Thus, emotional arousal was low when the deterrent was low, high when 
the deterrent was absent or moderate, and again low when the deterrent was high. Other emotions that have been manipulated in this way by altering the level of some deterrent include happiness, sympathy and wellbeing (Brehm, 1999).

In investigating the role of deterrents to emotions, Silvia and Brehm (2001) have found that a wide range of opposing stimuli can act in this capacity. Both deterrents that were merely anticipated (i.e., imagining an impediment to your goal) and deterrents that were neutral in valance (distraction in the form of white noise) were found to vary the emotional intensity in the hypothesised manner. Although it is predicted that the model will hold for an even broader range of emotions (Brehm, 1999), this has yet to be tested. The present study seeks to provide further support for this model by investigating how the emotions of guilt and self-forgiveness serve to motivate behavioural outcomes. Considering that neither of these emotions has previously been investigated within the context of the emotional intensity model, the present study seeks to provide additional support for the emotional intensity model by demonstrating its applicability to emotions and behaviours not previously studied in this manner. Furthermore, the present study will attempt to use Brehm's model of emotional intensity in conjunction with the Transtheoretical model to demonstrate how emotional arousal can stimulate progression and regression between the TTM stages of change.

An important, but often overlooked component of the emotional intensity model is the assumption that the strength of the urge for an action or goal is directly proportional to the strength of the intensity of the emotion associated with it. In other words, emotions that are experienced more intensely will produce stronger urges for some outcome. Given this assumption, it is to be expected that the achievement of a goal would be more likely 
when the emotional intensity associated with that goal is high. As discussed above, smoking is a behaviour that is likely to produce feelings of both guilt and selfforgiveness. According to the model of emotional intensity, these emotions are therefore, expected to motivate certain urges for behaviour connected to smoking. To further understand the types of behaviour guilt and self-forgiveness for smoking are likely to motivate, a distinction between active and passive emotions must be made.

\section{Active and Passive Emotions}

Active emotions, such as anger or fear, are associated with the urging of behaviour, whereas passive emotions, such as happiness or sadness, are not (Brehm \& Brummett, 1998). Anger may drive us to throw a punch, and fear may drive us to runaway. However, actions driven by feelings of happiness or sadness are less clear. Though we may laugh when we are happy and cry when we are sad, these actions are not the primary purposes of these emotions. Yet, in Brehm's view all emotions have the quality of motivational states. In this line, both active and passive emotions should create urges that lead to behaviour. This tenet of the emotional intensity is supported when one considers Frijda (1986): even "doing nothing" is a form of behaviour. Passive emotions can, therefore, be viewed as urging the maintenance of current behaviour, whereas active emotions urge new behaviour. Following this distinction, active emotions have been conceptualized as motivations for outcomes that are merely potentials; that is, outcomes that have not yet occurred. Conversely, passive emotions have been conceptualized as the result of the realization of some outcome; that is, outcomes that have already occurred (Brehm, 1999). As such, active emotions are concerned with the motivation of new behaviour, while passive emotions are concerned with maintaining the status quo. 
Although the intensity of both active and passive emotions has been found to vary with the level of deterrent in the manner proposed by Brehm (1999), the function of the deterrent is dependent on the type of emotion experienced. Specifically, deterrents to active emotions will be any factor that inhibits new action, while deterrents to passive emotions will be any factor that promotes new action.

Returning to the emotions of guilt and self-forgiveness experienced in response to continued smoking behaviour, it is argued that guilt is an active emotion that will stimulate new behaviour in the form of smoking abstinence. As discussed above, guilt is a problem-focussed emotion that motivates attempts at making reparations for the transgression committed (Tangney \& Dearing, 2002). Applying Brehm's model, when individuals experience the negative affect indicative of guilt in response to the commission of a transgression, the reduction in that negative affect becomes the desired outcome. Previous research has shown that individuals experiencing guilt can be motivated to undo the wrongdoing (Frijda, Kuipers, \& Ter Shure, 1989; Walster, Berscheid, \& Walster, 1973) by making reparations for the transgression they have committed (Ferguson \& Stegge, 1998; Lister, Wohl, Rocznik, \& Kuiken, 2005; Tangney, 1995). It then follows that the more guilty one feels for their transgression, the stronger their desire to remedy the wrong committed. One way in which a reduction of this negative affect can be achieved is through the making of reparations, such as making a commitment to not commit the transgression in the future. As such, guilt represents an active emotion that is likely to be deterred by factors that inhibit attempts at making reparations. In terms of the transgression of smoking, making the commitment to quit can 
be seen as such reparation. Deterrents to guilt in this case would be any factor that inhibits attempts at achieving smoking cessation.

Conversely, when individuals view themselves as transgressors, they may reduce negative affect by granting themselves forgiveness for the transgression. In this case, the making of reparations is circumvented. As such, self-forgiveness may be conceptualized as a passive emotion that motivates the maintenance of current behaviour. In terms of smoking behaviour, it is expected that individuals who forgive themselves for smoking would be less inclined to quit. Deterrents to self-forgiveness for smoking could therefore be any factor that stimulates the desire for smoking cessation.

\section{Deterrents to the Motivation of Smoking Cessation}

Although there are a variety of circumstances that may represent reasons for not feeling guilty, considering the lack of research in this area it seems appropriate to make use a rather conservative deterrent. That is, one that has been known to produce the desired effect in other studies of motivation. As noted earlier, task difficulty has been found to produce the proposed quadratic effect in several studies of motivation (e.g., Wright, et al., 1986) and therefore represents the quintessential deterrent for studies of emotional motivation as well. It is therefore proposed that perceived difficulty of smoking cessation will provide adequate deterrence to guilt to motivate arousal of this emotion.

As noted earlier, despite the fact that smoking poses serious risks to the health of both smokers and non-smokers, cessation of this behaviour is desired by less that $50 \%$ of young smokers (Health Canada, 2003). Other research has found that the level of severity of nicotine addiction is a good indicator of future smoking abstinence (Hyland et al., 
2004), suggesting that the harder it is to abstain from smoking, the less likely people are to attempt quit. Closely tied to the perceived difficulty of any task is the concept of selfefficacy. Self-efficacy has been conceptualized as the subjective beliefs individuals have about their own ability to perform goal directed actions (Bandura, 1977; 1997). As such, it has been identified by the Transtheoretical model as an important psychological construct in the facilitation of behavioural change. According to the TTM, progression toward the maintenance stage of change is marked by increasing levels of self-efficacy for smoking cessation. Although research has demonstrated that self-efficacy is predictive of abstinence (Amodei \& Lamb, 2005), stage of change has been found to be unaffected by self-efficacy as conceptualized by the TTM (Pearlman et al., 2004). This suggests that while increases in self-efficacy are related to an actual quit attempt, the effect of self-efficacy on varying levels of motivation for smoking cessation are less clear. There is evidence that self-efficacy is related to motivation for smoking cessation in a non-linear way. It has been shown that individuals high in self-efficacy who are in the action stage of change were more likely to relapse than individuals in the same stage who were lower in self-efficacy (Segan, Borland, \& Greenwood, 2002). Thus, as predicted by previous studies on motivation, the perception that smoking cessation would be easily achieved resulted in less motivation to remain smoking abstinent. Even more convincing evidence has come from a study which found that smokers in the contemplation stage reported the higher levels of self-efficacy than smokers in either precontemplation or preparation (De Vries, Mudde, Dijkstra, \& Willemsen, 1998). This suggests that motivation to quit smoking will be greatest when quitting is not seen as easily accomplished. The present study sought to build upon this research by exploring 
the relationship between the perceived difficulty of achieving smoking cessation and stage are also affected by the emotions of guilt and self-forgiveness.

In terms of guilt for smoking, the degree of difficulty ascribed to quitting may serve to reduce the confidence that reparations (in the form of smoking cessation) can be successfully made. Considering that the primary function of guilt is to stimulate efforts that will right the past wrong, the perceived difficulty of quitting smoking, which is one way of making reparations for the transgression of smoking, will act as a deterrent to guilt. Therefore, I argue that when the achievement of smoking abstinence is perceived to be easily accomplished it will be of low immediate concern, resulting in low levels of guilt and motivation for smoking cessation. As the perception of difficulty increases, guilt should be aroused to levels that will exceed the deterrent. At this point, achieving smoking abstinence is perceived to be not as easily accomplished and therefore of greater concern, resulting in the arousal of feelings of guilt and increased motivation for smoking cessation. When the achievement of smoking abstinence is viewed as very difficult or impossible, feelings of guilt may seem futile. At this point, feelings of guilt and motivation for smoking cessation should again drop to a low level.

When the perceived difficulty of smoking cessation is deemed to be too low or too high to warrant further feelings of guilt, self-forgiveness may be granted in its place, thereby facilitating the maintenance of the smoking behaviour. In this way, it can be argued that guilt and self-forgiveness are strongly related, and may even represent opposing points along a continuum. Despite the fact that they both represent reactions to wrong doings, little psychological research has explored their relationship. Preliminary studies of the correlations between trait levels of guilt and self-forgiveness have found 
that people with a tendency to self-forgive are somewhat less prone to guilt; however, this finding was not replicated in a second independent sample (Tangney, et al., 2005). This indicates that while the relationship between guilt and self-forgiveness is strong, they are likely best represented as two unique constructs. The present study seeks to further explore these how these constructs are related to one another by examining the degree to which they are experienced at differing levels of perceived difficulty of achieving smoking cessation.

\section{Summary}

Although the Transtheoretical model has identified distinct stages of change that smokers pass through as they increase in their motivation for smoking cessation, previous research investigating utility of specific psychological constructs believed to influence the transition between stages has been mixed. Application of Brehm's model of emotional intensity may be useful in this regard, as it proposes that emotions as motivational states directed at the achievement of some outcome or outcome potential, the intensity of which is a quadratic function of the level of some deterrent. The present study seeks to further investigate the postulates of both the TTM and the model of emotional intensity in the context of smoking cessation. Specifically, the present study aims to show how the arousal of guilt and the inhibition of self-forgiveness are affected by the perception of difficulty attributed to the achievement of smoking abstinence. Furthermore, the effect of this interplay of emotions and perceptions on present stage of change and future smoking status will also be investigated. 


\section{Chapter 2}

\section{The Present Study}

The present study sought to expand the model of emotional intensity proposed by Brehm and colleagues (Brehm 1999; Brehm \& Brummett, 1998) by showing how the intensity of guilt experienced in reaction to continued smoking behaviour is maximized by moderate levels of a deterrent in the form of perceived difficulty of the achievement of smoking cessation. This investigation augments the existing theory by exploring its applicability to an emotion (guilt), which has not previously been studied in this manner. Although the model of emotional intensity has been shown to effectively describe the relationship between experimentally manipulated emotions and deterrents, the present study attempted to increase the external validity of the model by investigating the interplay between naturally occurring emotions and deterrence.

The present study also tested the underlying assumption put forth by Brehm (1999) that the intensity of emotion are directly proportional to urges for some behavioural action by investigating the relationship between the emotional intensities of guilt and self-forgiveness and motivation for smoking cessation. If Brehm is correct in his assumption, we expected to find that high levels of guilt for smoking behaviour corresponded to a high desire for smoking cessation, while high levels of self-forgiveness corresponded to a low desire for smoking cessation. By using the stages of behavioural change as the measure of motivation, we also attempted to augment the TTM, which has been effective in assessing the likelihood for change, but not the process of change. By showing how these two theories work together, a clearer understanding of how desire for 
smoking cessation achieved will be obtained. Based on the aims mentioned above, the following hypotheses were made:

Hypothesis 1. It was proposed that the perception of quitting difficulty and feelings of self-forgiveness granted for continuing to smoke would predict feelings of guilt. Specifically, the relationship between perception of difficulty and feelings of guilt were expected to share a quadratic relationship, so that a) low levels of perceived difficulty associated with low levels of guilt; b) moderated levels of perceived difficulty associated with moderate to high levels of guilt; and c) high levels of perceived difficulty associated with low levels of guilt. The relationship between self-forgiveness and guilt was expected to be linear with low levels of self-forgiveness associated with high levels of guilt.

Hypothesis 2. It was proposed that perception of difficulty, self-forgiveness and guilt would each predict current stage of change. Specifically, it was expected that high levels of guilt would be indicative of individuals at the preparation stage, whereas low levels of guilt would be indicative of individuals at the precontemplation stage. Conversely, high levels of self-forgiveness were expected to be indicative of individuals at the precontemplation stage, while low levels of self-forgiveness were indicative of individuals at the preparation stage. Furthermore, the perception of difficulty is anticipated to interact with the relationship between the emotions and current stage of change so that guilt would be maximised when the perception of difficulty is moderate.

Hypothesis 3. Assuming that guilt and self-forgiveness are predictive of stage of change, it is proposed that guilt and self-forgiveness will mediated the relationship between stage of change and the other constructs of the TTM. Thus, it is expected that 
variance in stage of change attributed to the TTM variables will be better accounted for by the variables of guilt and self-forgiveness.

Hypothesis 4. Relationships established through Hypotheses 1 and 2 were expected to be predictive of successful smoking cessation. Specifically, it was expected that those individuals who experienced the most guilt and least self-forgiveness would be most likely to achieve smoking abstinence within five months. Conversely, it was expected that those who experience the most self-forgiveness for their present smoking behaviour would be the least likely to achieve smoking abstinence within five months.

\section{Method}

\section{Participants and Procedure}

Participants were introductory psychology students attending a large eastern Canadian university. At the beginning of the academic year, the Department of Psychology distributed a battery of questionnaires to all introductory psychology students. Contained in this battery was an item that asked students to indicate their current smoking status. Students were considered smokers if they answered "Yes" to the question "Are you currently a smoker?". From the preselection, we were able to identify and make contact with 138 smokers of which 96 (69.6\%) agreed to participate. Because students are not required to complete the preselection battery, we used the psychology department on-line research sign-up board to recruit an additional 99 student smokers. Four non-student participants were also recruited through their personal acquaintance with the primary researcher ${ }^{1}$. From this sample of 199 participants, 13 were eliminated because they were not current smokers. The final sample included a total of 186 current

\footnotetext{
${ }^{1}$ All participants, even those known previously to the researchers, were blind as to the specific hypotheses of the study, and were told only that it was study investigating feelings and behaviours regarding personal smoking behaviour.
} 
smokers (64 men, 122 women). The mean age of the sample was 20.78 years ( $\mathrm{SD}=$ $3.71)$.

Once enrolled in the study, participants were given a three-digit identification number that was used to link the data collected during the first assessment with data collected at the follow-up assessment. Prior to completing the measures, participants were informed that they would be completing a set of questionnaires that would asses their current smoking behaviour as well as their thoughts and attitudes towards smoking. Although all measures were completed online by accessing a secure URL that was supplied to the participants by the researchers, 141 participants completed the measures during prescheduled sessions hosted by the researcher that took place in an on-campus computer lab, while 67 participants were given the URL for the questionnaire via the internet and completed the questionnaires at a time and place of their choosing. Analysis of these two questionnaire formats revealed no differences on the key variables of stage of change, guilt, self-forgiveness or perceived difficulty. These analyses are described in Appendix E.

After the questionnaire was completed, the data were submitted electronically and emailed to the researchers. Participants were then asked for their consent to be contacted to participate in an additional follow-up assessment that was to take place in approximately five months. Nine participants did not consent to being contacted. Those who withheld their consent did not differ from the other participants on any of the key variables. These analyses are described in detail in Appendix E. As a "thank you" for participating, all participants were given the option of either course credit or a $\$ 2$ gift certificate to a campus coffee shop. 
Five month after completing the initial assessment, participants were contacted via email to complete the follow-up questionnaire that assessed progression, maintenance or regression in stage of change as well as additional measures of daily cigarette consumption and efforts towards becoming smoking abstinent. All participants completed the questionnaire at a time and place of their choosing. Eighty-seven ( $46.8 \%$ of the total sample; 32 men, 55 women) participants completed this follow-up. No significant differences in any variable were observed between completers and non completers. These analyses are described in Appendix E.

\section{Measured Variables}

Motivation for smoking cessation. The Transtheoretical model stages of behavioural change were used to assess motivation for smoking cessation (DiClemente, et al., 1991; Velicer et al., 1995). An individual's stage was determined by using the of 3-item Stage of Change measure. The first item of this measure establishes smoking status (current, former and never a smoker). The second item assesses number of times the individual has quit smoking for at least 24 hours in the last year. The third item assesses intention to quit and current stage of change with the question "Are you seriously thinking of quitting smoking" to which the individual may answer "yes, in the next 30 days"; "yes in the next 6 months"; or "no, not thinking of quitting". Current smokers were classified as being in the preparation stage if they were intending to quit in the next 30 days and had at least one 24-hour quit attempt in the last year. Current smokers who were intending to quit in the next 30 days, but did not have a 24-hour quit attempt in the last year, and current smoking intending to quit in the next six months were classified as being in the contemplation stage. Current smokers who were not intending to quit were classified as 
being in the precontemplation stage. Previous research has demonstrated that this classification system is an effective measure of motivation for smoking cessation as it has been found to be predictive of both previous quit attempts (Pearlman, et al. 2004) and future smoking abstinence (DiClemente, et al., 1991; Fava, et al., 1995; Prochaska, et al., 2004; Segan, et al., 2004).

Guilt. Guilt was assessed using the State Shame and Guilt Scale (SSGS; Tangney \& Dearing, 2002). The SSGS consists of 5 statements designed to reflect current feelings of guilt. Statements focus on the wrongfulness of some transgression (e.g., I feel bad about something I have done). Participants are asked to rate the extent to which each statement is indicative of how they are feeling at present using a scale that ranges from 1 (Not feeling this way at all) to 5 (feeling this way very strongly). Responses were reversed scored as necessary so that higher score reflect higher levels of guilt. For the purposes of the current study the instructions of this measure were modified to ensure that only feelings towards personal smoking behaviour were assessed. Cronbach's alphas for the guilt subscale were been found to be .77 , indicating good internal consistency.

When people fail in their attempt to quit there exist two sources of potential guilt: 1) guilt for continued smoking, and 2) guilt for failing to quit. Considering that the present study is concerned with different levels of motivation for cessation, the assessment of guilt experienced in response to continued smoking behaviour was of interest. This was achieved by modifying the instructions of the questionnaire so that only feelings towards one's smoking behaviour are assessed.

Self-forgiveness. A modified version of the 7-item state forgiveness measure (Brown \& Phillips, in press) was used to assess self-forgiveness. The original measure 
was comprised of seven statements that reflect decreases in avoidance and retribution desires towards an offender as well as reductions in more general feelings of hostility towards an offender and has demonstrated excellent internal reliability $(\alpha=.91 ;$ Brown $\&$ Phillips, 2005). To assess self-forgiveness for the specific transgression of smoking we altered the wording of items 1 to 5 to reflect the respondents' smoking behaviour as the object of forgiveness. Items 6 (I hope this person gets what's coming to them for what they did to me) and 7 (If I saw this person again, I would try to avoid interacting with him/her) of the original were eliminated as because they could not adequately be reworded to reflect self-forgiveness. As such, these two items were replaced with two new items (I criticise myself because of my smoking; I put myself down because of my smoking) designed to assess hostility towards the self. Participants were instructed to indicate their agreement with each statement using a sale that ranges from 1 (strongly disagree) to 7 (strongly agree). Items were reversed scored as necessary so that higher scores will be reflective of higher levels of self-forgiveness experienced in response to continued smoking behaviour. In our sample, the modified measure also demonstrated good internal consistency, alpha $=.82$

Perceived quitting difficulty. Perception of quit difficulty was assessed with three items that reflect personal feeling about ability to quit smoking. The items reflect perceived ease of quitting (i.e., "How easy would it be for you to quit and never smoke again?" (adapted from the Robert Wood Johnston Substance Abuse Policy Research Project, reported in Weinstein et al., 2004), certainty of success (i.e., "If you decided to quit smoking, how sure would you be that you would be successful?"), and ability to quit (i.e., "Do you feel you would have the ability to quit smoking if you wanted to?"). 
Reponses are made by selecting from three responses that reflect low, moderate, and high degrees of easiness, sureness and ability. A total difficulty score is achieved by find the average of the three items. Cronbach's alpha for this measure was .82, demonstrating good internal consistency.

Perception of smoking behaviour as a transgression. For any measures of guilt and self-forgiveness for smoking to be meaningful, smoking must be viewed as a transgression. Perception of smoking as a transgression will also be assessed with the items "Smoking causes serious health problems" and "Whenever possible people should not smoke," to which participants may answer either "yes," or "no." A response of yes or both of these items will indicate that smoking is viewed as a negative behaviour.

Smoking Pros and Cons. The short-form decisional balance inventory (Velicer, DiClemente, Prochaska, \& Brandenberg, 1985), which is comprised of two subscales representing pros and cons of smoking, is a measure of attitudes towards the benefits and risks of smoking. The measure has demonstrated good factorial invariance across categories of gender, age and race (Ward, Velicer, Rossi, Fava, \& Prochaska, 2004). Higher scores on the pros scale indicate a more positive view of smoking, while high scores on the cons scale indicate a more negative view of smoking. The correlation between the two subscales was not significant $r=.08, p=.27$. 
Table 1

Correlations among decisional balance subscales

(Cronbach's $\alpha$ s on the diagonal)

\begin{tabular}{lll}
\hline & Smoking Pros & Smoking Cons \\
\hline Smoking Pros & .65 & \\
Smoking Cons & .08 & .68 \\
\hline
\end{tabular}

Self-Efficacy and Temptations. The Self-Efficacy and Temptations Inventory (Velicer, DiClemente, Rossi, \& Prochaska, 1990) was developed to measure level of selfefficacy to overcome certain cues often associated with smoking. The short form of the scale is comprised of nine situations where smoking is likely to be desirable. For each situation, participants are asked rate their level of temptation to smoke using a five-point scale that ranges from 1 "Not at all tempted" to 5 "Extremely tempted". The situations can be further categorised into three subscales that represent positive/social situations (e.g., with friends at a party), negative affective situations (e.g., When I am very anxious and stressed), and habitual situations (e.g., When I first get up in the morning). The scale is based on a longer 20 -item scale that has demonstrated good internal consistency with coefficient alphas for the three subscales ranging from .80 to .95 (Velicer, et al., 1990). Correlations between the subscales are presented in Table 2. 
Table 2

Correlations among self-efficacy/temptations subscales

(Cronbach's $\alpha$ s on the diagonal)

\begin{tabular}{lccc}
\hline & $\begin{array}{c}\text { Positive Affective } \\
\text { / Social }\end{array}$ & $\begin{array}{c}\text { Negative } \\
\text { Affective }\end{array}$ & $\begin{array}{c}\text { Habitual / } \\
\text { Craving }\end{array}$ \\
\hline Positive Affective / Social & .49 & & \\
Negative Affective & $.48^{*}$ & .86 & .60 \\
Habitual / Craving & $.62^{*}$ & $.50^{*}$ & .60 \\
\hline$* p<.01$ & & & \\
\hline
\end{tabular}

Transtheoretical Model Processes of Change. The short form of the process of change measure (Prochaska, Velicer, DiClemente, \& Fava, 1988) is comprised of 20 statements about covert or overt activities that individuals may engage in as they attempt to quit smoking. The measure assesses use of ten different processes of change that fall into one of the four broader categories of Experiential, Behavioural, Reevaluation and Management. The Experiential category represents increased attention to information about smoking information (consciousness raising) and the negative effects of smoking on the environment (environmental). The Behavioural category reflects efforts towards seeking social support (helping relationships), rewards received for not smoking (reinforcement), overcoming temptations (counter conditioning) and self-encouragement (self-liberation). Reevaluation reflects emotional responses to smoking, including having negative thoughts associated with smoking (self-reevaluation), awareness of changing social views (social liberation), and emotional reaction to the negative effects of smoking (dramatic relief), whereas Management refers to the removal of smoking cues (stimulus control). Participants are asked to indicate how frequently they engage in each activity 
using a scale that ranges from 1 (Never) to 5 (Repeatedly) so that high scores reflect increased activity aimed at smoking cessation.

Table 3

Correlations among process of change subscales

(Cronbach's $\alpha$ s on the diagonal)

\begin{tabular}{lcccc} 
& Experiential & Revealuation & Behavioural & Management \\
\hline Experiential & .74 & & & \\
Revealuation & $.57^{*}$ & .68 & & \\
Behavioural & $.39^{*}$ & $.39^{*}$ & .70 & .79 \\
Management & $.46^{*}$ & $.48^{*}$ & $.41^{*}$ &. \\
\hline
\end{tabular}

Smoking cessation. Cessation of smoking will be assessed using information regarding stage of change collected during the follow-up assessment. Participants who have progressed to the either the action or maintenance stage at the time of the follow-up will be considered to have achieved abstinence. Stage advancement and reductions in daily cigarette consumption will also be assessed as measure of behavioural change. 


\section{Chapter 3}

\section{Results}

\section{Smoker Demographics}

Analysis of the sample revealed there to be 55 individuals in the Precontemplation stage, 84 individuals in the Contemplation stage and 44 individuals in the Preparation stage. Three participants did not respond to the question regarding intent to quit and were excluded from analyses where stage of change was a variable. Most participants (146, $78.5 \%$ ) reported making a previous attempt at quitting, within the last year. Data regarding previous quit attempts was missing for twenty-five participants. The mean number of cigarettes smoked per day was $7.38(\mathrm{SD}=5.68)$.

\section{Perception of Smoking as a Transgression}

Responses to the statement items "Smoking causes serious health problems" and "Whenever possible people should not smoke," were analysed to validate the assumption that smoking is viewed as a form of transgression. Over ninety-seven percent of participants agreed with the first statement while over eighty-five percent agreed with the second. Ninety-eight percent agreed with at least one of the statements, indicates that smoking was viewed as a behaviour that has at least the potential for harm for the majority of the participants with only two participants answering negatively to both statements ${ }^{1}$. This confirms our assumption that smoking can be viewed as a transgression to which feeling of guilt and self-forgiveness may be experienced.

\footnotetext{
1 These participants were removed from further analysis, as the concepts of guilt and self-forgiveness can only be experienced when one is aware of the transgression they have committed.
} 
Table 1

Perceptions of smoking as a transgression

\begin{tabular}{lcccc}
\hline Item & $f$ & $\%$ & Cum \% \\
\hline Smoking causes health problems & Yes & 204 & 97.6 & 97.6 \\
& No & 5 & 2.4 & 100.0 \\
People should quit & & & & \\
& Yes & 179 & 85.6 & 85.6 \\
& No & 30 & 14.4 & 100.0 \\
Yes to one statement & & 29 & 13.9 & 13.9 \\
Yes to both statements & & 177 & 84.7 & 98.6 \\
No to both statements & 3 & 1.4 & 100.0 \\
\hline
\end{tabular}

\section{Gender Differences}

Independent samples t-tests revealed significant differences for men and women on several of the variables of interest (see Table 5 for means and standard deviations). To control the presence of significant effects due entirely to chance, a family confidence level was set at .90 . Therefore, the type I error rate for each individual test was set at $.10 / 14=.007$. Results revealed that men reported less guilt, $t(182)=-2.80, p<.007$ and more self-forgiveness, $t(182)=3.58, p<.001$ for their smoking behaviour than women did. Women reported higher levels of smoking cons, $t(182)=-4.20, p<.001$ and reported more temptations in negative situations, $t(182)=-4.10, p<.001$. Women also reported a higher level of use of the reevaluation, $t(182)=-4.38, p<.001$, and behavioural, $t(182)=-2.84, p<.007$ processes. A trend for women to feel more tempted in positive affective/social situations was also observed, $t(182)=-2.75, p=.007$. Given that gender differences were found for the key variables of guilt and self-forgiveness, as 
well as for several of the TTM construct variables, all further analyses were conducted for men and women separately. Likewise, the results of these analyses are presented separately for men and women.

Table 2

Descriptive Statistics (Means, SDs) as a Function of Gender

\begin{tabular}{|c|c|c|c|c|c|c|}
\hline & & Males & & & Females & \\
\hline & $n$ & Mean & $S D$ & $n$ & Mean & $S D$ \\
\hline Age & 63 & 20.97 & 3.21 & 121 & 20.69 & 3.94 \\
\hline Cigarettes per day & 63 & 7.48 & 6.04 & 121 & 7.43 & 5.51 \\
\hline Guilt & 63 & 2.20 & 0.88 & 121 & $2.57 *$ & 0.84 \\
\hline Forgiveness & 63 & 4.54 & 1.17 & 121 & $3.92 * *$ & 1.10 \\
\hline Perceived Difficulty & 63 & 1.52 & 0.39 & 121 & 1.68 & 0.49 \\
\hline \multicolumn{7}{|l|}{ Decisional Balance } \\
\hline Smoking Pros & 63 & 2.84 & 086 & 121 & 3.02 & 0.88 \\
\hline Smoking Cons & 63 & 2.30 & 0.88 & 121 & $2.88 * *$ & 0.90 \\
\hline \multicolumn{7}{|l|}{ Self-efficacy } \\
\hline \multicolumn{7}{|l|}{ Temptations } \\
\hline $\begin{array}{l}\text { Positive Affective / } \\
\text { Social }\end{array}$ & 63 & 3.50 & 0.76 & 121 & 3.81 & 0.71 \\
\hline Negative Affective & 63 & 3.58 & 1.08 & 121 & $4.19 * *$ & 0.88 \\
\hline Habitual / Craving & 63 & 2.68 & 0.86 & 121 & 2.85 & 0.98 \\
\hline \multicolumn{7}{|l|}{ Processes of Change } \\
\hline Experiential & 63 & 2.27 & 0.80 & 121 & 2.58 & 0.87 \\
\hline Reevaluation & 63 & 2.56 & 0.67 & 121 & $3.01 * *$ & 0.66 \\
\hline Behavioural & 63 & 2.67 & 0.55 & 121 & $2.95^{*}$ & 0.69 \\
\hline Management & 63 & 1.67 & 0.78 & 121 & 1.76 & 0.97 \\
\hline
\end{tabular}


Stage Differences for Women

The variables of interest were compared across Stage of Change observed at the initial assessment using Multivariate Analysis of Variance (MANOVA). A significant Wilks's lambda of $.53, F(28,204)=2.73, p<.001$ was obtained for the female participants. Means, standard deviations and results of Tukey post hoc comparisons for all of the variables of interest are reported in Table 6.

The variables of interest were compared across Stage of Change observed at the initial assessment using Multivariate Analysis of Variance (MANOVA). A significant Wilks's lambda of $.53, F(28,204)=2.73, p<.001$ was obtained for the female participants. Means, standard deviations and results of Tukey post hoc comparisons for all of the variables of interest are reported in Table 6.

Cigarette consumption. Differences in the number of daily cigarettes smoked were observed over the three stages $F(2,115)=3.83, p<.05$. Consistent with previous research (Etter, 2004), women in the precontemplation stage were found to smoke more cigarettes per day $(M=9.43, S D=6.53$ than women in the preparation stage $(M=5.50$, $S D=4.58), p<.05$.

Guilt. Women who were motivated to quit smoking were found to report a greater level of guilt than did women with no desire for change, $F(2,115)=13.56, p<.001$. Tukey post hoc comparisons revealed significant differences in guilt between women in the precontemplation stage $(M=1.97, S D=0.68)$ and the contemplation stage $(M=2.68$, $S D=0.84), p<.001$, as well as the preparation stage $(M=2.99, S D=0.68), p<.001$. However, no differences in guilt were observed between the stages of contemplation and preparation. 
Self-Forgiveness. Differences in self-forgiveness $F(2,115)=12.55, p<.001$ were observed between each of the three stages. Specifically, self-forgiveness as associated with decreased motivation for change as women in the precontemplation stage reported experiencing more self-forgiveness $(M=4.59, S D=1.05)$, than women in the contemplation stage $(M=3.88, S D=1.01), p<.01$, who experienced more selfforgiveness than women in the preparation stage $(M=3.27, S D=0.95), p<.05$.

Quitting Difficulty. Difference degrees of perceived quitting difficulty were also observed at different stages, $F(2,115)=7.11, p<.01$. Comparisons of the different stages revealed that women in the precontemplation stage perceived quitting to be more $\operatorname{difficult}(M=1.94,0.65), p<.001$ than women in the contemplation $(M=1.68, S D=$ $0.37), p<.05$ and preparation $(M=1.48, S D=0.44), p<.01$ stages. As with guilt, no differences in perceived difficulty were observed between contemplation and preparation.

Smoking Pros and Cons. Although no differences in the pros of smoking were observed, $F(2,115)=0.09, n s$, stage differences were found for the cons of smoking $F(2$, $115)=8.16, p<.001$. Women in the precontemplation stage reported more negative views of smoking, $(M=2.38, S D=0.78)$ than women in contemplation $(M=2.89, S D=$ $0.84), p<.05$, or preparation $(M=3.29, S D=0.94), p<.001$ stages.

Processes of Change. Significant stage differences were observed for the reevaluation, $F(2,115)=47.66, p<.001$, behavioural, $F(1,179)=50.55, p<.001$, and management, $F(1,179)=30.23, p<.001$ processes of change, with more frequent use associated with being in a more advanced stage. Women in the preparation stage reported greater use of the revaluation processes $(M=3.39, S D=0.58)$, compared to both women in the contemplation $(M=3.04, S D=0.65), p<.05$, and precontemplation $(M=2.58, S D$ 
$=0.48), p<.001$. Women in the preparation stage also reported making greater use of the behavioural processes $(M=3.33, S D=0.70)$ than women in contemplation $(M=2.96$, $S D=0.66), p<.05$, and precontemplation $(M=2.52, S D=0.51), p<.001$. The same pattern was observed for the management processes, as women in the preparation stage used these processes more often $(M=2.32, S D=1.13)$ than did women in the contemplation $(M=1.73, S D=0.86), p<.01$, or precontemplation stage $(M=1.18, S D$ $=0.51), p<.001$.

Stage Differences for Men

A second MANOVA was conducted to test for significant stage differences on the variables of interest for the male participants. This analysis resulted in a significant Wilks's lambda of $.30, F(28,94)=2.74, p<.001$. Means, standard deviations and results of Tukey post hoc comparisons for all of the variables of interest are reported with those for women in Table 6 .

Guilt. As was observed for women, significant effects were found for guilt, $F(2$, $60)=14.32, p<.001$. Post hoc comparisons revealed that, as for women, men in precontemplation $(M=1.64, S D=0.47)$ also experienced less guilt than men in contemplation $(M=2.42, S D=0.82), p<.01$, or preparation $(M=2.87, S D=0.96) . p<$ .001 . 
Table 1

Descriptive Statistics (Means, SDs) for Men and Women as a Function of Time 1 Stage of Change

\begin{tabular}{|c|c|c|c|c|c|c|c|c|c|c|}
\hline & & ontempl & ion & & templa & $\mathrm{n}$ & & Preparatic & & \\
\hline & $N$ & Mean & $S D$ & $N$ & Mean & $S D$ & $n$ & Mean & $S D$ & Tukey HSD \\
\hline Age & & & & & & & & & & \\
\hline Women & 28 & 20.07 & 2.83 & 60 & 20.95 & 4.22 & 30 & 20.93 & 4.43 & - \\
\hline Men & 26 & 21.35 & 4.14 & 23 & 20.70 & 2.62 & 14 & 20.71 & 2.05 & - \\
\hline Cigarettes per day & & & & & & & & & & \\
\hline Women & 28 & 9.43 & 6.53 & 60 & 7.63 & 5.24 & 30 & $5.50 *$ & 4.58 & $\mathrm{PC}>\mathrm{PR}$ \\
\hline Men & 26 & 7.04 & 6.67 & 23 & 7.48 & 4.79 & 14 & 8.28 & 6.94 & - \\
\hline Guilt & & & & & & & & & & \\
\hline Women & 28 & 1.97 & 0.68 & 60 & 2.68 & 0.84 & 30 & $2.99 * * *$ & 0.68 & $\mathrm{PC}<\mathrm{CO}=\mathrm{PR}$ \\
\hline Men & 26 & 1.64 & 0.47 & 23 & 2.42 & 0.82 & 14 & $2.87 * * *$ & 0.96 & $\mathrm{PC}<\mathrm{CO}=\mathrm{PR}$ \\
\hline Forgiveness & & & & & & & & & & \\
\hline Women & 28 & 4.59 & 1.05 & 60 & 3.88 & 1.01 & 30 & $3.27 * * *$ & 0.95 & $\mathrm{PC}>\mathrm{CO}>\mathrm{PR}$ \\
\hline Men & 26 & 5.36 & 0.72 & 23 & 4.19 & 1.16 & 14 & $3.61 * * *$ & 0.97 & $\mathrm{PC}>\mathrm{CO}=\mathrm{PR}$ \\
\hline Difficulty & & & & & & & & & & \\
\hline Women & 28 & 1.94 & 0.65 & 60 & 1.68 & 0.37 & 30 & $1.48 * *$ & 0.44 & $\mathrm{PC}>\mathrm{CO}=\mathrm{PR}$ \\
\hline Men & 26 & 1.41 & 0.39 & 23 & 1.74 & 0.32 & 14 & $3.61 * *$ & 0.37 & $\mathrm{PC}<\mathrm{CO}>\mathrm{PR}$ \\
\hline Smoking Pros & & & & & & & & & & \\
\hline Women & 28 & 3.09 & 0.95 & 60 & 3.02 & 0.77 & 30 & 3.01 & 1.03 & - \\
\hline Men & 26 & 2.78 & 0.87 & 23 & 2.91 & 0.84 & 14 & 2.83 & 0.91 & - \\
\hline Smoking Cons & & & & & & & & & & \\
\hline Women & 28 & 2.38 & 0.78 & 60 & 2.89 & 0.84 & 30 & $3.29 * * *$ & 0.95 & $\mathrm{PC}<\mathrm{CO}=\mathrm{PR}$ \\
\hline Men & 26 & 1.86 & 0.67 & 23 & 2.51 & 0.80 & 14 & $2.76 * *$ & 1.02 & $\mathrm{PC}<\mathrm{CO}=\mathrm{PR}$ \\
\hline $\begin{array}{l}\text { Positive Affective/ } \\
\text { Social }\end{array}$ & & & & & & & & & & \\
\hline Women & 28 & 3.76 & 0.72 & 60 & 3.89 & 0.84 & 30 & 3.79 & 0.94 & - \\
\hline Men & 26 & 3.42 & 0.85 & 23 & 3.65 & 0.55 & 14 & 3.40 & 0.88 & - \\
\hline
\end{tabular}


Table 6

Descriptive Statistics (Means, SDs) for Men and Women as a Function of Time 1 Stage of Change (Continued)

\begin{tabular}{|c|c|c|c|c|c|c|c|c|c|c|}
\hline 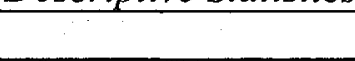 & \multicolumn{3}{|c|}{ Precontemplation } & \multicolumn{3}{|c|}{ Contemplation } & \multicolumn{3}{|c|}{ Preparation } & \multirow[b]{2}{*}{ Tukey HSD } \\
\hline & $N$ & Mean & $S D$ & $N$ & Mean & $S D$ & $n$ & Mean & $S D$ & \\
\hline \multicolumn{11}{|l|}{ Negative Affective } \\
\hline Women & 28 & 4.15 & 0.98 & 60 & 4.25 & 0.83 & 30 & 3.79 & 0.68 & - \\
\hline Men & 26 & 3.19 & 1.24 & 23 & 4.10 & 0.67 & 14 & $3.45^{*}$ & 1.03 & $\mathrm{PC}<\mathrm{CO}=\mathrm{PR}$ \\
\hline \multicolumn{11}{|l|}{ Habitual / Craving } \\
\hline Women & 28 & 2.93 & 1.10 & 60 & 2.93 & 0.92 & 30 & 2.67 & 0.93 & - \\
\hline Men & 26 & 2.63 & 1.00 & 23 & 2.69 & 0.68 & 14 & 2.76 & 0.91 & - \\
\hline \multicolumn{11}{|l|}{ Experiential } \\
\hline Women & 28 & 2.30 & 0.72 & 60 & 2.64 & 0.95 & 30 & 2.78 & 0.84 & - \\
\hline Men & 26 & 1.82 & 0.58 & 23 & 2.61 & 0.74 & 14 & $2.55 * * *$ & 0.89 & $\mathrm{PC}<\mathrm{CO}=\mathrm{PR}$ \\
\hline \multicolumn{11}{|l|}{ Reevaluation } \\
\hline Women & 28 & 2.58 & 0.48 & 60 & 3.04 & 0.65 & 30 & $3.39 * * *$ & 0.59 & $\mathrm{PC}<\mathrm{CO}<\mathrm{PR}$ \\
\hline Men & 26 & 2.17 & 0.53 & 23 & 2.78 & 0.62 & 14 & $2.90 * * *$ & 0.66 & $\mathrm{PC}<\mathrm{CO}=\mathrm{PR}$ \\
\hline \multicolumn{11}{|l|}{ Behavioural } \\
\hline Women & 28 & 2.52 & 0.51 & 60 & 2.96 & 0.66 & 30 & $3.33 * * *$ & 0.70 & $\mathrm{PC}<\mathrm{CO}<\mathrm{PR}$ \\
\hline Men & 26 & 2.33 & 0.48 & 23 & 2.77 & 0.45 & 14 & $3.13 * * *$ & 0.44 & $\mathrm{PC}<\mathrm{CO}=\mathrm{PR}$ \\
\hline \multicolumn{11}{|l|}{ Management } \\
\hline Women & 28 & 1.18 & 0.51 & 60 & 1.72 & 0.86 & 30 & $2.32 * * *$ & 1.13 & $\mathrm{PC}<\mathrm{CO}<\mathrm{PR}$ \\
\hline Men & 26 & 1.36 & 0.70 & 23 & 1.87 & 0.76 & 14 & $1.67 *$ & 0.78 & $\mathrm{PC}=\mathrm{CO}=\mathrm{PR}$ \\
\hline
\end{tabular}

$* p<.05 ;{ }^{* *} p<.01 ; * * * p<.001$ 
Quitting Difficulty. Differences in perceived quitting difficulty were significant $F(2,60)=6.60, p<.01$, and even stronger for men than for women. Consistent with previous research (De Vries, et al., 1998) men with a moderate level of motivation for smoking cessation had a higher mean level of perceived difficulty $(M=1.73, S D=0.32$ ), men in either the precontemplation stage $(M=1.41, S D=0.72), p<.01$, or the preparation stage $(M=1.38, S D=0.37), p<.05$.

Smoking Pros and Cons. As with the women, stage differences were not found for the pros of smoking, $F(2,60)=0.70, n s$, but were found for the cons of smoking $F(2,60)$ $=7.03, p<.01$. Post hoc comparison revealed that men in the precontemplation $(M=$ $1.86, S D=0.67$ ) stage reported less negative views of smoking than did men in the contemplation $(M=2.51, S D=0.80), p<.05$, or preparation $(M=2.76, S D=1.02), p<$ .01 .

Self-Efficacy Temptations. Although no difference in any of the temptations situations were observed for the female participants, men did show significant stage differences for the negative affective situations subscale $F(2,60)=4.99, p<.01$. Higher mean levels of temptations in these situations was found among men in the contemplation stage $(M=4.10, S D=0.67)$, than among men in the precontemplation stage $(M=3.19$, $S D=1.24), p<.05$.

Processes of Change. As was found for the women, stage effects were observed for the reevaluation, $F(2,60)=9.38, p<.001$, behavioural, $F(2,60)=14.82, p<.001$, and management, $F(2,60)=3.78, p<.05$ processes of change. Unlike the women, differences were also observed for the experiential processes $F(2,60)=8.87, p<.001$. 
Post hoc comparisons revealed that men in the precontemplation stage $(M=1.82, S D=$ 0.58) made more less use of the experiential processes than did men in either contemplation, $(M=2.61, S D=0.74), p<.01$, or preparation $(M=2.55, S D=0.89), p<$ .01 . The reevaluation processes were used less frequently by men in the precontemplation stage $(M=2.17, S D=0.53)$, than did men in contemplation $(M=2.78, S D=0.62), p<$ .01 , or preparation $(M=2.90, S D=0.66), p<.01$. Men in the precontemplation stage $(M$ $=2.33, S D=0.48), p<.05$, also used the behavioural processes less frequently than did men in the stages of contemplation $(M=2.78, S D=0.45), p<.05$, or preparation $(M=$ $3.12, S D=0.44), p<.05$. Although the main effect of the management processes was significant, post hoc comparisons revealed only a marginally significant difference between men in the precontemplation stage $(M=1.36, S D=0.70)$ and men in contemplation stage $(M=1.87, S D=0.76), p=.06$, or prepatation stage $(M=1.93, S D=$ 0.83) $p=.07$.

\section{Guilt, Self-Forgiveness and Perceived Quitting Difficulty}

Based on Brehm's theory of emotional arousal, it was expected that feelings of guilt would be greatest at moderate levels of perceived quit difficulty, and that this relationship would coincide with decreased feelings of self-forgiveness. A multiple regression analysis was conducted to evaluate the strength of perceived quit difficulty and self-forgiveness as predictors of guilt. According to Brehm's theory of emotional arousal, emotions are greatest when deterrents to their function are moderate. In line with this view, we expected to observe a quadratic relationship between guilt and difficulty, where high levels of guilt would be predicted by moderate levels of perceived difficulty. 
To obtain a quadratic effect coefficient for perceived difficulty with the linear regression model, difficulty scores were squared. The model therefore included selfforgiveness, a linear difficulty variable and a squared difficulty variable as predictors of guilt. To control for multicollinearity between the two difficulty variables, difficulty scores first centred around the mean (as suggested by Neter, Kutner, Nachtsheim, \& Wasserman, 1996). The model was then tested for women and men separately. Results for Women

The combination of self-forgiveness and the difficulty variables was significantly related to measure of guilt, $R^{2}=.72 F(3,117)=42.01, p<.001$. Zero-order correlations revealed that although increased self-forgiveness was related to lower feelings of guilt, perceived quitting difficulty was not (see Table 7). Thus, although self-forgiveness was predictive of guilt, perceived quit difficulty was not. This is contrary to the prediction that difficulty would act as a deterrent to guilt.

Results for Men

A similar pattern of results was observed for the male participants. Although the overall combination of predictors was significant, $R^{2}=.85, F(3,59)=50.97, p<.001$, as with the women, this was attributed to the strong associations between guilt and selfforgiveness. Neither the linear measure of difficulty, nor the squared variable were related to guilt. The correlations and beta weights for both men and women are presented in Table 7. 
Table 1

Regression Analyses Predicting Guilt from Self-Forgiveness and Perceived Quitting

Difficulty

\begin{tabular}{lcccccc}
\hline & \multicolumn{3}{c}{ Women } & \multicolumn{2}{c}{ Men } \\
\hline & $r$ & $\beta$ & $R^{2}$ & $r$ & $\beta$ & $R^{2}$ \\
\hline & & & .72 & & & .85 \\
Forgiveness & $-.71^{*}$ & $-.55^{*}$ & & $-.85^{*}$ & $-.64^{*}$ & \\
Difficulty (linear) & -.00 & .08 & & .21 & -.04 & \\
Difficulty (quadratic) & -.08 & -.22 & & -.14 & .18 & \\
\hline
\end{tabular}

$* p<.001$

Stage of Change, Guilt, Self-Forgiveness and Perceived Quit Difficulty

It was expected that the emotional arousal of guilt and subsequent decrease of self-forgiveness would be predictive of stage of change. Although the expected arousal of guilt by perceived difficulty was not observed, we tested all three variables (guilt, selfforgiveness and perceived difficulty) as predictors of stage of change using a multinomial logistic regression model ${ }^{1}$. This form of analysis necessitates the use of a meaningful reference category. Since the main goal of the present study was to observe differences in the emotions of guilt and self-forgiveness at each preactive stage of change, preparation was chosen as the reference category. This allowed for comparisons between the most

\footnotetext{
${ }^{1}$ Accroding to Neter, et al., (1996), discriminant analysis may be used as an alternative to multinomial logistic regression when all predictors are continuous variables. Although both tests were conducted with the data set and revealed very similar results, the results of the multinomial regression analysis are reported as this test allows for direct comparisons between individuals at the preparation stage and individuals in each of the other two stages. Multinomial regression also allowed for the computation of odds ratios that would indicate the how increases in the independent variables increase or decrease the likelihood being in a particular stage. Furthermore, the results of this test were intended to be used in later mediational analyses, which can not be tested using discriminant analyses.
} 
highly motivated individuals and individuals who were either moderately or not at all motivated to quit smoking. The data presented here is thus interpreted as increased (Odds ratio $>1.00$ ) or decreased (Odds ratio $<1.00$ ) odds of being in either the contemplation or precontemplation stages compared with being in the preparation stage given a one-unit increase in the predictor. Parameter estimates $(B)$, standard errors of B (SE B) and odds rations (OR) with 95\% confidence intervals for women and men are presented in Table 8. Results for women

Membership in at least one stage other than preparation was significantly predicted by guilt, self-forgiveness and perceived difficulty. The odds of being in the precontemplation stage (and thus, less motivation to quit) rather than the preparation stage were $0.32(95 \% \mathrm{CI}=0.10-.94)$ times less for each one-point increase in guilt. This indicates that guilt was positively related to motivation for change. On the other hand, granting oneself forgiveness was found to correspond to decreased motivation for change. With the other variables held constant, the odds of being in the precontemplation stage rather than the preparation stage were $2.60(95 \% \mathrm{CI}=1.10-6.17)$ times higher for each one-point increase in self-forgiveness. Self-forgiveness was also predictive of the contemplation stage, as the odd odds of being in this stage increased as self-forgiveness increased $(\mathrm{OR}=1.95,95 \% \mathrm{CI}=1.04-3.66)$. Increases in perceived difficulty also increased the odds of being in both the precontemplation ( $\mathrm{OR}=16.03,95 \% \mathrm{CI}=3.61-$ 71.23) and contemplation stages ( $\mathrm{OR}=4.23,95 \% \mathrm{CI}=1.04-3.66)$.

Comparisons between the observed stages and the predicted values based on the predictors revealed a concordance rate of 65.3 percent. However, as seen in Table 9 , the 
variable demonstrated much more utility in predicting the stages of contemplation and precontemplation than preparation.

Results for Men

Unlike results observed for the female participants, guilt was not predictive of any stage for men. The odds of being in the precontemplation stage rather than the preparation stage were found to be $7.04(95 \% \mathrm{CI}=1.45-34.26)$ times greater for every one-point increase in self-forgiveness, with guilt and perceived difficulty held constant. Conversely, for the men, the odds of being in the contemplation stage rather than the preparation stage were increased as the perceived difficulty of quitting increased $(O R=$ $39.37,95 \% \mathrm{CI}=2.86-541.20)$.

Concordance rates for observed and predicted stage were higher for men than for women at 71.4 percent (see Table 9). Although the combination of variables was most predictive of precontemplation, the concordance rates for contemplation and preparation were also quite high.

In sum, for all participants, higher levels of self-forgiveness and perceived quitting difficulty were associated with being less motivated for smoking cessation. However, these effects were stronger for women than for men. For women only, guilt was also predictive of stage, with increases in this emotion increasing the likelihood of being motivated for smoking cessation. 
Table 2

Results of Multinomaial Logistic Regressions with Guilt, Self-Forgiveness and Difficulty Predicting Stage of Change Conducted for Women and Men Separately

\begin{tabular}{|c|c|c|c|c|c|}
\hline Measures & $\chi^{2}$ & $B$ & SE B & OR & $95 \% \mathrm{CI}$ \\
\hline \multicolumn{6}{|l|}{ Women } \\
\hline Guilt & $6.88 *$ & & & & \\
\hline PR vs. $\mathrm{CO}$ & & -0.03 & 0.41 & 0.97 & $0.44-2.16$ \\
\hline PR vs. PC & & $-1.17^{*}$ & 0.57 & 0.31 & $0.10-0.94$ \\
\hline Self-Forgiveness & $6.22 *$ & & & & \\
\hline PR vs. $\mathrm{CO}$ & & $0.67 *$ & 0.32 & 1.95 & $1.04-3.66$ \\
\hline PR vs. PC & & $0.96 *$ & 0.44 & 2.60 & $1.10-6.17$ \\
\hline Quit Difficulty & $16.81 * * *$ & & & & \\
\hline PR vs. $\mathrm{CO}$ & & $1.44^{*}$ & 0.61 & 4.23 & $1.03-14.08$ \\
\hline PR vs. PC & & $2.77 * * *$ & 0.76 & 16.03 & $3.61-72.23$ \\
\hline \multicolumn{6}{|l|}{ Men } \\
\hline Guilt & 0.27 & & & & \\
\hline PR vs. $\mathrm{CO}$ & & 0.04 & 0.79 & 1.04 & $0.22-4.87$ \\
\hline PR vs. PC & & -0.39 & 0.93 & 0.69 & $0.11-4.25$ \\
\hline Self-Forgiveness & $6.73^{*}$ & & & & \\
\hline PR vs. $\mathrm{CO}$ & & 0.95 & 0.74 & 2.58 & $0.61-10.89$ \\
\hline PR vs. PC & & $1.95^{*}$ & 0.81 & 7.04 & $1.45-34.26$ \\
\hline Quit Difficulty & $11.30 * *$ & & & & \\
\hline PR vs. $\mathrm{CO}$ & & $3.67 * *$ & 1.34 & 39.37 & $2.86-541.20$ \\
\hline PR vs. PC & & 2.09 & 1.41 & 8.08 & $0.50-129.39$ \\
\hline
\end{tabular}


Table 3

Concordance Rates for Observed and Predicted Stage of Change for Women and Men

Observed Stage Predicted Stage

\begin{tabular}{rcccc}
\hline & PC & CO & PR & \% Correct \\
\hline Precontemplation (PC) & 19 & 7 & 2 & 67.9 \\
Men & 22 & 3 & 1 & 84.6 \\
Contemplation (CO) & & & & \\
Women & 6 & 50 & 4 & 83.3 \\
Men & 5 & 14 & 4 & 60.9 \\
Preparation (PR) & & & & \\
Women & 0 & 22 & 8 & 26.7 \\
Men & 2 & 3 & 9 & 64.3 \\
Overall Percentage & & & & 65.3 \\
Women & 21.2 & 66.9 & 11.9 & 71.4 \\
\hline Men & 46.0 & 31.7 & 22.2 & \\
\hline
\end{tabular}

Mediational Models.

As mentioned previously, a part from the staging model, the TTM details several behaviours and cognitions that are believed to be indicative of the process of change. Considering that guilt and self-forgiveness were found to be predictive of current stage, their relationship to the constructs presented in the TTM was explored using a series of Baron and Kenny (1986) mediational analyses. From the results of the MANOVA (see Table 6), it was observed that the stages of change was differentiated by the cons of smoking and reevaluation, behavioural and management processes. For men, negative affective temptations and the experiential processes also differentiated the stages. 
Therefore, the relationships between these variables and stage of change were tested for potential mediating effects of guilt (women only) and self-forgiveness.

Since it was the mediating role of guilt and forgiveness on each TTM variable that was of primary importance, and not the relationships between them, a series of multiple logistic regression analyses were conducted to test the individual effect of each TTM variable on stage of change. This approached had been employed previously by Grucza, Przybeck and Cloninger (2005) to test the mediational effect of personality factors on known risk factors for suicide. Although this would reduce the possibility of type I errors, it was accepted that the type II error would be elevated. Another series of logistic regression analyses were then conducted with guilt (women only) and forgiveness entered individually into the model. Mediation was assumed to have occurred if the emotional variable was predictive of stage, and its inclusion reduced the odds ratio of the TTM variable to an insignificant level (i.e., OR approaching 1.00). Chi square likelihood ratios, odds ratios (OR) with $95 \%$ confidence intervals before and after inclusion of the mediator(s) are presented in Tables 10, 11, and 12.

\section{Mediation for Women}

Increases in the cons of smoking, reevaluation processes, behavioural processes, and management processes significantly decreased the odds of being in at least one stage other than preparation (see Tables 10 and 11). After the addition of guilt to the models, the cons of smoking was no longer a significant predictor of the precontemplation stage $(\mathrm{OR}=0.48,95 \% \mathrm{CI}=.22-1.04)$, or the contemplation stage $(\mathrm{OR}=.66,95 \% \mathrm{CI}=0.38$ -1.16). However, increases in guilt did continue to significantly increase the likelihood 
of being in the precontemplation stage rather than the preparation stage, indicating mediation of the cons of smoking by guilt.

The inclusion of the forgiveness variable to the model also significantly reduced the utility of cons of smoking in predicting precontemplation $(\mathrm{OR}=.50,95 \% \mathrm{CI}=0.23-$ 1.09), whereas forgiveness remained a significant predictor of the precontemplation stage (see Table 11). This indicates that forgiveness also mediates the relationship between negative views of smoking and stage of change.

Mediation for Men

The cons of smoking, experiential processes, reevaluation processes, behavioural processes, and management processes significantly decreased the odds of being in at least one stage compared to preparation. As was found for the women, after self-forgiveness were added to the model, cons of smoking was no longer a significant predictor of precontemplation $(\mathrm{OR}=0.68,95 \% \mathrm{CI}=0.22-2.11)$. The inclusion of self-forgiveness also invalidated the experiential processes $(\mathrm{OR}=0.63,95 \% \mathrm{CI}=0.18-2.20)$, the reevaluation processes $(\mathrm{OR}=0.70,95 \% \mathrm{CI}=0.13-3.75)$, and the management processes $(\mathrm{OR}=1.13,95 \% \mathrm{CI}=0.35-3.61)$, as predictors of precontemplation. In all models, however, self-forgiveness significantly predicted stage differences, indicating mediation by this variable (see Table 12). 
Table 4

Results of Mediational Analyses for Women with Guilt as the Mediator

\begin{tabular}{lccccc}
\hline $\begin{array}{c}\text { Mediator or } \\
\text { Independent } \\
\text { Variable }\end{array}$ & & \multicolumn{2}{c}{ PR vs. PC } & \multicolumn{2}{c}{ PR vs. CO } \\
\hline \multicolumn{1}{c}{$\chi^{2}$} & OR & $95 \%$ CI & OR & $95 \%$ CI \\
\hline Guilt & $25.21^{* * *}$ & $0.17^{* * *}$ & $0.08-0.38$ & 0.61 & $0.34-1.08$ \\
Cons & $15.78^{* * *}$ & $0.28^{* * *}$ & $0.14-0.56$ & $0.60^{*}$ & $0.36-0.99$ \\
& $(3.86, n . s)$. & $(0.48)$ & $(0.22-1.04)$ & & \\
Reevaluaiton & $25.54^{* * *}$ & $0.09^{* * *}$ & $0.03-0.26$ & $0.40^{*}$ & $(0.19-0.85)$ \\
& $\left(8.89^{*}\right)$ & $\left(0.18^{* *}\right)$ & $(0.05-0.60)$ & & \\
Behavioural & $21.61^{* * *}$ & $0.13^{* * *}$ & $0.05-0.35$ & $0.41^{*}$ & $0.20-0.84$ \\
& $\left(18.23^{* * *}\right)$ & $\left(0.13^{* * *}\right)$ & $(0.04-0.37)$ & & \\
& $25.45^{* * *}$ & $0.13^{* * *}$ & $0.04-0.40$ & $0.56^{*}$ & $0.36-0.88$ \\
& $\left(12.21^{* *}\right)$ & $\left(0.21^{* *}\right)$ & $(0.07-0.63)$ & &
\end{tabular}

Note: Bracketed values represent results after inclusion of the mediator.

$\mathrm{PR}=$ Preparation $; \mathrm{CO}=$ Contemplation $; \mathrm{PC}=$ Precontemplation' $\mathrm{OR}=$ odds ratio $; \mathrm{CI}=$ confidence interval.

$* p<.05, * * p<.001, * * * p<.001$ 
Table 5

Results of Mediational Analyses for Women with Self-Forgiveness as the Mediator

\begin{tabular}{lccccc}
$\begin{array}{l}\text { Mediator or } \\
\text { Independent } \\
\text { Variable }\end{array}$ & & & & & \\
& $\chi^{2}$ & OR & $95 \%$ CI & OR & $95 \%$ CI \\
\hline Self- & $23.25^{* * *}$ & $3.79^{* * *}$ & $2.05-7.03$ & $1.79^{*}$ & $1.14-2.82$
\end{tabular}

Forgiveness

Cons

$$
15.78 * * * \quad 0.28 * * * \quad 0.14-0.56 \quad 0.60 * \quad 0.36-0.99
$$
$(3.17$, n.s. $)$
$(0.76)$
$(0.42-1.38)$
$(0.76)^{a}$
$(0.42-1.38)$

Reevaluation

$$
25.54 * * *
$$

$0.09 * * *$

$(0.03-0.26)$

$0.40^{*}$

$(0.19-0.85)$

$(0.18 * *)$

$(0.05-0.64)$

$(0.59)^{\mathrm{a}}$

$(0.24-1.43)$

Behavioural

$$
21.61 * * *
$$

$0.13 * * *$

$0.05-0.35$

$0.41 *$

$0.20-0.84$

$\left(18.46^{* * *}\right)$

$\left(0.13^{* * *}\right)$

$(0.04-0.36)$

$\left(0.44^{*}\right)$

$(0.21-0.92)$

Management

$25.45^{* * *}$

$0.13 * * *$

$0.04-0.40$

$0.56 *$

$0.36-0.88$

(14.24**)

$\left(0.18^{* *}\right)$

$(0.06-0.56)$

$(0.63)^{\mathrm{a}}$

$(0.40-1.02)$

Note: Bracketed values represent results after inclusion of the mediator.

$\mathrm{PR}=$ Preparation $; \mathrm{CO}=$ Contemplation $; \mathrm{PC}=$ Precontemplation' $\mathrm{OR}=$ odds ratio $; \mathrm{CI}=$ confidence interval.

$* p<.05, * * p<.001, * * * p<.001$

${ }^{a}$ self-forgiveness not predictive of stage. 
Table 6

Results of Mediational Analyses for Men with Self-Forgiveness as the Mediator

\begin{tabular}{|c|c|c|c|c|c|}
\hline \multirow[t]{2}{*}{$\begin{array}{l}\text { Mediator or } \\
\text { Independent } \\
\text { Variable }\end{array}$} & \multirow[b]{2}{*}{$\chi^{2}$} & \multicolumn{2}{|c|}{ PR vs. PC } & \multicolumn{2}{|c|}{ PR vs. $\mathrm{CO}$} \\
\hline & & OR & $95 \% \mathrm{CI}$ & OR & $95 \% \mathrm{CI}$ \\
\hline Self-Forgiveness & $29.55 * * *$ & $7.41 * * *$ & $2.76-19.86$ & 1.87 & $0.89-3.96$ \\
\hline \multirow[t]{2}{*}{ Cons } & $13.25 * *$ & $0.24 * *$ & $0.09-0.60$ & 0.70 & $0.32-1.55$ \\
\hline & $(0.67$, n.s. $)$ & $(0.68)$ & $(0.22-2.11)$ & & \\
\hline \multirow[t]{2}{*}{ Experiential } & $16.54 * * *$ & $0.21 * *$ & $0.07-0.62$ & 1.10 & $0.46-2.64$ \\
\hline & $(4.19$, n.s. $)$ & $(0.63)$ & $(0.18-2.20)$ & & \\
\hline \multirow[t]{2}{*}{ Reevaluation } & $17.19 * * *$ & $0.11 * *$ & $0.03-0.44$ & 0.70 & $0.23-2.16$ \\
\hline & $(2.43$, n.s. $)$ & $(0.70)$ & $(0.13-3.75)$ & & \\
\hline \multirow[t]{2}{*}{ Behavioural } & $25.99 * * *$ & $0.01 * * *$ & $0.00-0.12$ & $0.14 *$ & $0.02-0.81$ \\
\hline & $(11.69 * *)$ & $(0.03 * *)$ & $(0.00-0.30)$ & $(0.18)^{a}$ & $(0.03-1.01)$ \\
\hline \multirow[t]{2}{*}{ Management } & $7.72 *$ & $0.34 *$ & $0.13-0.87$ & 0.92 & $0.41-2.05$ \\
\hline & $(0.26$, n.s. $)$ & (1.13) & $(0.35-3.61)$ & & \\
\hline
\end{tabular}

Note: Bracketed values represent results after inclusion of the mediator.

$\mathrm{PR}=$ Preparation $; \mathrm{CO}=$ Contemplation $; \mathrm{PC}=$ Precontemplation $; \mathrm{OR}=$ odds ratio $; \mathrm{CI}=$ confidence interval.

${ }^{*} p<.05, * * p<.001, * * * p<.001$

${ }^{a}$ self-forgiveness not predictive of stage. 
Factors Associated with Behavioural Change

Given that the combination of guilt, self-forgiveness and quit difficulty were significant predictors of stage of change, and therefore motivation for smoking cessation, it was expected that they would also be predictive of actual behaviours associated with smoking cessation. Efforts towards becoming smoking abstinent may take the form of many different behaviours. For this reason several outcomes measures, which included the achievement of smoking abstinence, progression to a more advanced stages of change and reduction were assessed.

Smoking Abstinence. Participants were assumed to be abstinent from smoking if they identified themselves as someone who had quit smoking within the last five months. Nine women and eight men reported having quit smoking. Binary logistic regression analysis was conducted with previous stage of change, guilt, self-forgiveness and perceived quit difficulty entered as predictors of two levels of smoking abstinence (i.e., quit, did not quit). As seen in Table 13, for women, increased perceived difficulty increased the likelihood of being smoking abstinent at the follow-up (OR $=.034,95 \% \mathrm{CI}$ $=.00-.51)$. However, this relationship was not observed for the male participants. Guilt, self-forgiveness and previous stage of change failed to predict abstinence for either gender.

Stage advancement. To create a dichotomous measure of stage advancement (i.e., advanced, did not advance), each stage was first coded with a numeric value so that higher values represented more advanced stages $(1=$ precontemplation, $2=$ contemplation, etc.). The value of stage of change observed at the time of the follow-up 
assessment was subtracted from the value for stage observed at the initial assessment.

Participants were deemed to have advanced in stage of change if the difference between these two stage values was equal or greater than 1 . Stepwise binary logistic regression analysis was again conducted with the same predictors. Sixteen women and twelve men were found to have advanced at least one stage. For both men and women, this advancement was not predicted by any of the variables included in the model

Table 7

Abstinence predicted by Guilt, Self-Forgiveness, and Difficulty

\begin{tabular}{lccccc}
\hline \multicolumn{1}{c}{ Measures } & $\chi^{2}$ & $B$ & SE B & OR & $95 \%$ CI \\
\hline Women & $11.90^{*}$ & & & & \\
Stage & & & & & \\
$\quad$ Contemplation & & 0.42 & 1.08 & 1.53 & $0.18-12.76$ \\
$\quad$ Precontemplation & & 0.48 & 1.26 & 1.62 & $0.14-19.28$ \\
Guilt & -0.49 & 0.75 & 0.61 & $0.14-2.67$ \\
Self-Forgiveness & & -0.64 & 0.56 & 0.52 & $0.17-1.59$ \\
Difficulty & & $-3.39^{*}$ & 1.38 & 0.03 & $.01-0.51$ \\
Men & 3.00 & & & & \\
Stage & & & & & \\
$\quad$ Contemplation & & -1.20 & 1.21 & 0.30 & $0.03-3.23$ \\
$\quad$ Precontemplation & & -1.88 & 1.49 & 0.15 & $0.01-2.84$ \\
Guilt & & 0.37 & 0.87 & 1.44 & $0.26-8.01$ \\
Self-Forgiveness & & 0.54 & 0.68 & 1.72 & $0.46-6.48$ \\
Difficulty & & 1.08 & 1.20 & 2.94 & $0.28-31.04$ \\
\hline
\end{tabular}

Reduced cigarette consumption. To ascertain information regarding changes in cigarette consumption, the daily number of cigarettes consumed at the time of the initial 
assessment was subtracted from the daily amount consumed at the time of the followup assessment so that negative values were indicative of reduces consumption, whereas positive values and zeros were indicative of maintained or increased consumption. To control for differences that were more aptly due to errors in participant recall, only negative differences less than one standard deviation of the mean daily consumption rate $(\mathrm{SD}=5.68$, as assessed at the initial assessment $)$ to be indicative of reduced consumption. All participants who were abstinent from smoking at the time of the followup were also included in the analyses as having reduced their cigarette consumption. This classification system led to thirteen women and eight men being labelled as reducers. Stepwise binary logistic regression was conducted to determine if the variables would predict reduced cigarette consumption. Results of this analysis failed to find a significant predictor that exceeded the $\mathrm{p}<.05$ cut-off. However, there was a trend where higher levels of perceived difficulty lead to decreased likelihood of reducing cigarette consumption $(\mathrm{OR}=0.26,95 \% \mathrm{CI}=0.06-1.13)$. 


\section{Chapter 4}

\section{Discussion}

The transtheoretical model of behavioural change (TTM) was created to describe the process whereby smokers become motivated for and achieve abstinence from smoking (Prochaska \& DiClemente, 1983, 1986). Although the model has been successful at predicting those individuals most motivated to change (DiClemente, et al., 1991; Fava, Velicer \& Prochaska, 1995; Pearlman, Wernicke, Thorndike \& Haage, 2004; Prochaska, Velicer, Prochaska, \& Johnson, 2004; Segan, Borland \& Greenwood, 2004), the factors associated with increases in motivation for change have been unclear. This lack of understanding of the differences between smokers at different levels of motivation for smoking cessation not only reduces the utility of the TTM staging model, but it also limits the utility of interventions that are targeted towards increasing a willingness to quit in all smokers. The present study sought to address this issue by examining how the emotions of guilt and self-forgiveness were related to differences in motivation for smoking cessation. High levels of guilt were expected to coincide with a high degree of motivation for smoking cessation. Conversely, high levels of self-forgiveness were expected to be associated with lower degrees of motivation to quit smoking. Furthermore, guilt and self-forgiveness, along with previous levels of motivation were expected to lead to future behaviours aimed at becoming smoking abstinent.

Gender Differences

Several unanticipated gender differences were observed in the present study. Women were found to experience more guilt for smoking than did their male counterparts. These differences could be attributed to general tendencies, as previous 
research has consistently shown that women experience more guilt, overall, than do their male counterparts (Fisher \& Exline, 2006; Walter \& Burnaford, 2006). One explanation for this gender disparity has come from Benetti-McQuoid and Bursik (2005), who investigated the effect of gender and gender roles on levels of dispositional guilt and guilt-proneness (i.e., the propensity to experience guilt in certain situations). They found that, whereas men were more likely to experience higher levels of dispositional guilt, women were more likely to experience guilt for specific behaviours. This difference was explained through gender role identification, as the adoption of a more traditionally feminine interpersonal style (e.g., deferring to friends, making amends, putting oneself in the service of others), by both men and women, was related to increased guilt proneness. Thus, people experience more situational guilt when they are concerned with the maintenance of social relationships. Applied to smoking behaviour, guilt for continuing to smoke may increase when the interpersonal and societal pressures to do so are high and meaningful.

Female smokers also reported a lower level of self-forgiveness than did male smokers. Recent research suggests women find the process of self-forgiveness to be more effortful than do men (Fisher \& Exline, 2006), and so this difference could have resulted from men simply finding forgiveness to be an easier task than the women did. Recent discussions of self-forgiveness have made a distinction between purposeful and thoughtful "real" self-forgiveness, conceptualized as a process of careful selfexamination whereby acceptance of responsibility for a transgression as well as a commitment to making reparations for the offence is achieved (Hall \& Fincham, 2005), 
and a simpler, pseudo self-forgiveness that can take place in the absence of a sincere acknowledgement of wrongdoing and acceptance of responsibility (Hall \& Fincham, 2005; Tangney, et al., 2005). It is possible that women find forgiveness to be a more arduous task than men do because they are more likely to engage in real self-forgiveness, while men are more likely to engage in pseudo self-forgiveness.

The observed gender differences in both guilt and self-forgiveness may also be explained by differences in how male and female smokers are perceived by others. A qualitative study of college smokers has found that while males who smoke were generally viewed favourably, female smokers were viewed negatively (Nichter, et al., 2006). Male smokers were described as "manly" and "in control", whereas women who smoked were described as "trashy" and "unlady-like." Furthermore, these judgements were made by both the male and female participants, all of whom were smokers themselves. Given this difference in how smoking is viewed for women and men, it follows that women would view smoking as a more serious transgression and would not only experience more guilt for smoking than do men, but would also experience less selfforgiveness as well.

Women smokers also reported more negative views of smoking, more frequent use of the reevaluation and behavioural processes, as well as more temptations in negative affective situations than did the male smokers. This suggests that though women may be more likely view smoking as something they should quit, and may also take more steps towards quitting, they are also more likely to be tempted to smoke in times of stress. 
Stage Differences

Different levels of guilt were observed between the precontemplation stage and the other two stages, with higher levels associated with increased motivation for change. Conversely, higher levels of self-forgiveness were associated with less motivation for change. This supports the hypothesis that guilt facilitates motivation for smoking cessation, whereas self-forgiveness inhibits motivation.

A major goal of the present study was to demonstrate how the perception of quitting difficulty arouses feelings of guilt for continuing to smoke. Analysis of the data failed to find a significant relationship between guilt and perceived quitting difficulty, indicating that quitting difficulty was not a sufficient deterrent to arouse feelings of guilt. Though past studies of Brehm's model have relied on experimentally manipulated emotions and deterrents, the present study relied on naturally occurring and self-reported perceptions of difficulty. Although the difficulty scale used allowed for scores to fall between 1.00 and 3.00 , over ninety-five percent of the sample had scores that fell between 1.00 and 2.33 , which represents low to moderate levels of difficulty. Thus, it is possible that this particular sample of smokers simply did not perceive quitting to be difficult enough to achieve adequate arousal of guilt. Young smokers have been shown to underestimate the addictively of cigarettes and their own levels of addiction (Amos, Wiltshire, \& Haw, 2006; Slovic, 2000), and so it would be expected that they would underestimate the difficulty they would have quitting as well. Experimental manipulation of the difficulty variable would allow for greater control over the perception of quitting difficulty and may be more successful at arousing feelings of guilt. 
Prediction of Stage

Although different levels of guilt were found at the each of the different stages of change for both genders, this emotion was only predictive of motivation among the women. Furthermore, higher levels of guilt only increased the likelihood of being in the preparation stage, compared to the precontemplation stage.

Self-forgiveness was found to have the opposite effect of guilt, with high levels of self-forgiveness associated with increased likelihood of being in the precontemplation stage rather than the preparation stage for men, and increased likelihood of being in both the contemplation and precontemplation stages for women. Thus, although guilt was influential in the promotion of motivation, self-forgiveness was an even more powerful inhibitor of the desire for change.

Perceptions of quit difficulty were also found to influence motivations for smoking cessation for both men and women. Specifically, it was found that women smokers who anticipate quitting smoking to be very difficult are more likely to be in the precontemplation or contemplation stages rather than the preparation stage, whereas among men, increases in the perception of quitting difficulty increase the likelihood of being in the precontemplation stage rather than the preparation stage. This finding is consistent with previous research that has shown that smokers who expect less difficulty quitting are more likely to become abstinent in the future (Curry, Thompson, Sexton, \& Omenn, 1989; Nebot, \& Cabezas, 1992) 
Elucidation of the TTM was also a goal of the present study. As such, the TTM variables were tested for potential differences according to stage of change. Significantly differentiated variables were also tested for the mediating effects of guilt and selfforgiveness. In our sample, increases in the cons of smoking and the reevaluation, behavioural, and management processes of change subscales significantly increased the likelihoods of being in the preparation stage for both genders. The experiential processes also predicted stage for men only. This finding is consistent with previous research that failed to find stage differences based on the self-efficacy and temptations constructs (Pearlman et al., 2004).

For both men and women, self-forgiveness mediated the relationship between the cons of smoking. Self-forgiveness also mediated the relationship between stage and the experiential, reevaluation, and management processes for male smokers, and guilt was found to mediate the relationship between the cons of smoking and stage for women.

The cons of smoking represents a recognition of the potential losses associated with smoking, and the experiential and reevaluation processes encompass increased attention to anti-smoking societal views, the impact of smoking on the environment, and negative emotional responses to smoking. Taken together, these constructs can be said to represent an increased awareness of the negative effects of smoking. Thus, the results indicate that when smokers pay attention to the negative consequences of smoking (i.e., poorer health, harm to environment) they are more likely to report greater motivation to 
quit when they are also less willing to forgive themselves for continuing to quit. For women, this awareness coupled with guilt also produces increases in motivation.

The management process (also known as stimulus control) represents overt behaviours directed at reminding the self not to smoke. Self-forgiveness was also found to mediate the relationship between this process and motivation to quit smoking in men only. This implies that male smokers will take actions towards smoking cessation only when they do not forgive themselves for smoking.

The TTM has recently come under attack by researchers who argue that there are better models of assessing changes in smoking behaviour (Sutton, 2001; West, 2005). For example, West (2005) has argued that the TTM should be abandoned in favour of a model that takes into account unconscious motivations. In showing how the emotions of guilt and self-forgiveness are related to both stage of change and the cons and experiential processes constructs, the present study has both supported and augmented TTM. Although imperfect, the TTM remains a practical tool that can be very successful when used to guide interventions aimed at facilitating smoking cessation (Aveyard, et al., 2001; Prochaska et al., 2005). The added information regarding how these construct function with certain emotions will only serve to strengthen its utility Prediction of Behavioural Change

Of guilt, self-forgiveness, difficulty and previous stage of change, only perceived quitting difficulty was found to increase the likelihood of making an actual behavioural change towards smoking cessation. Among the female smokers, the perception that smoking would be less difficult was found to increase the likelihood of being abstinent 
from smoking at the five-month follow-up. This finding is supported by previous research that has found perceptions of quitting difficulty to be highly predictive of future smoking cessation (Kennett, Morris, \& Bangs, 2006; Nierkens, Stronks, van Oel, \& de Vries, 2005).

Although guilt and self-forgiveness were found to predict increases in motivation and intentions towards quitting, neither emotion predicted actual behaviours aimed at quitting. This finding is supported by the fact that while perceptions of smokers are far less favourable for women than for men (Nichter et al., 2006), the world-wide smoking rate among women is expected to rise by $20 \%$ by the year 2025 (Brundtland, 2001). In other words, women, in general, may feel bad about their smoking, but this may not diminish their willingness to start smoking, nor increase their willingness to take steps towards quitting.

Recently, granting oneself forgiveness for failed quit attempts, as opposed to forgiveness for continuing to smoke, has been found to increase the likelihood of future cessation (Matthew, 2004). This suggests that successful smoking cessation is facilitated through changes in the levels and focus of certain emotions. For example, whereas increasing feelings of guilt and decreasing feelings of self-forgiveness for continuing to smoke may stimulate a desire for smoking abstinence (as was shown in the present study), once attempts at quitting are made, increasing self-forgiveness may actually help to keep smokers motivated for change. 


\section{Limitations}

The rather young age range of our sample makes the findings hard to generalize to the general population. Young smokers may defer significantly from their older counterparts in their attitudes towards smoking as well as knowledge of its effects. Contemporary young adults have been inundated with anti-smoking information all their lives and may therefore be more sensitive to and trusting of that information. They may see smoking as less socially acceptable and therefore may be less likely to forgive themselves for engaging in a behaviour they have always known is bad for them. This may not be the case with older smokers who started smoking at a time when it was socially acceptable to do so. Older smokers may have trouble viewing their behaviour as a transgression against the self. Thus, idea that one can be forgiving or unforgiving of ones self for smoking may seem strange or even preposterous to smokers that began smoking before the negative effects of smoking became widely available and accepted. Decreasing self-forgiveness may therefore not be as important to the motivation for abstinence in older smokers. Considering that young smokers are most at risk for becoming life-long smokers (Alvarado \& Breslau, 2005), there remains a lot to be gained from the study of factors that are of importance to this specific group.

Another limitation to the present study was the small number of participants who were willing to complete the follow-up assessment. This resulted in an even smaller number of people who had made behavioural changes towards becoming smoking abstinent. According to Grimm and Yarnold (1995) accurate hypothesis testing with logistic regression analysis requires fifty cases per independent variable. Our follow-up 
sample fell far below this at twenty-nine participants per variable. Splitting the sample along gender also served to reduce the number of participants who made behavioural changes. However, despite the low power of the tests, there was a trend for perceived difficulty to predict reduced cigarette consumption among male smokers. The results of this study should therefore be interpreted with some caution. It is possible that with a higher follow-up response rate, effects for guilt, self-forgiveness and perceived difficulty would have reached a significant level. Considering that these variables were predictive of motivation for change, future research is needed before their utility in predicting behavioural changes can be dismissed.

As previously mentioned, the use of self-reported perceived difficulty may have resulted in a lack of participants that did not feel quitting smoking would be very difficult (as is necessary for adequate demonstration of emotional arousal). Inducing perceptions of difficulty would have controlled for this, and may have resulted in the hypothesized quadratic relationship with guilt. The use of self-reported measures of guilt and selfforgiveness may have also impacted the results of the study. Although higher guilt scores were observed for women in the preparation stage, the mean guilt score at this stage was only 2.99. Considering guilt items were rated using a seven-point scale, it would be inaccurate to say that these women were feeling very guilty about their smoking. As was noted, the young age of the sample may have impacted the degree of guilt experienced. Young smokers have yet to experience serious health problems due to their smoking. Thus, the transgression component of smoking may be one of anticipated harm, rather 
than current harm. Guilt may therefore be experienced at a reduced degree than would be expected by older populations of smokers.

Although the present study was successful in differentiating between smokers not at all motivated for change from those most motivated for change, there was a marked lack of differentiation between smokers who want to quit right away and smokers who intend to quit, but have no immediate plans to do so. For women, the odds of being in the precontemplation stage rather than the preparation stage increases as guilt increased, however guilt did not affect the odds of being in the contemplation stage. Similarly, for the male smokers, increased self-forgiveness increased the likelihood of being in the precontemplation stage, but not the contemplation stage, rather than the preparation stage. The experiential and cons subscales of the TTM also failed to differentiate contemplation from preparation. For the stages of the TTM to be valid measures of the change process, there must be differences in meaningful factors. Identification of those factors that separate one stage from another are critical to our understanding of how people become increasingly motivated to quit smoking and would do much to guide interventions aimed at that end.

Caution should also be taken when interpreting some of the results due to low internal reliability of measures used in the present study. For example, the obtained Cronbach's alphas for the positive affective/social $(\alpha=-.49)$ and the habitual/craving $(\alpha$ $=.60)$ temptation situations were considerably low. It is therefore not surprising that significant effects were not observed for these variables. In terms of the positive affective / social temptations, the variation in responses may have been due to the broad range of 
situations assessed with the individual items. Although many purely social smokers would have no doubt responded positively to being tempted "at a party", it is possible that few of these smokers would have endorsed "over coffee" or "with my spouse or close friend" as situations in which they were very tempted. The inconsistency in the habitual / craving subscale may have also been due to differences between social and regular smokers. Social smokers typically smoke fewer cigarettes than regular smokers, and may therefore be less addicted and therefore less tempted in habitual situations than regular smokers. However, since the present study did not differentiate between social smokers and regular smokers, it remains unclear if this was the reason for the lack of internal consistency in these subscales. It should be noted that the short form of the Selfefficacy / Temptations measure was used rather than the long version, which also may have led to more consistent responding. However, considering the number of measures used, reducing participant fatigue was a more important concern.

\section{Future Research}

As noted, subsequent investigations which examine guilt over a wider range of perceived quitting difficulty is needed. Also needed are future studies that investigate the utility of guilt and self-forgiveness in predicting quitting related behaviours. The observed utility of guilt and self-forgiveness as predictors of motivation for smoking cessation should cause us to wonder what other emotions are important to the facilitation and inhibition of a desire to become abstinent from smoking.

There is now a growing literature on gender differences in the process of smoking cessation (e.g., McKee, et al., 2005; Reynoso, Susabda, \& Cepeda-Benito, 2005; Wetter, 
et al., 2004). Although previous research has found that stage of change differ for men and women (Dijkstra, et al., 1992; O’Hea, Wood \& Brantley 2003), other investigations of the TTM have largely ignored the influence of gender (e.g., Anderson \& Keller, 2002; Herzog, et al., 1999; Rosen, 2000; Segan, et al., 2002; Shumann, et al., 2005; Velicer, Hughes, Fava, \& Prochaska, 1995). The present study found gender differences in several of the TTM constructs. For male smokers, different levels of temptations in negative affective situation and the experiential processes differentiated the three preactive stages of change, however, these differences were not observed for the women. Female smokers were also found to make more use of the reevaluation and behavioural processes than men. This finding suggests there is a need for a better understanding of the differences in how the constructs of the TTM are used by men and women. In so doing, interventions that make use of the TTM will only increased in their ability to predict the specific factors best describe how change is facilitated and accomplished.

\section{Concluding Remarks}

Although guilt has been traditionally thought of as a negative emotion, Tangney and Dearing (2002) has proposed that feelings of guilt for can stimulate prosocial changes in behaviour. The present study has found support for this view by showing that female smokers who are unmotivated to quit smoking experience significantly lower levels of guilt than do smokers who are motivated to quit. Motivation for smoking cessation was also predicted by lowered levels of self-forgiveness, giving further support that forgiving the self for negative habits can lead to maintenance of that behaviour (Tangney, et al., 2005). 
The present study was guided by two theories; Brehm's (1999) theory of

emotional arousal and the Transtheoretical Model of Behavioural Change (Prochaska \& DiClemente, 1983, 1986). Although in the sample used guilt was not aroused by perceived difficulty as the emotional arousal model would suggest, other tenets of the theory were upheld. Guilt, an active emotion, was found to coincide with a desire for smoking cessation, while self-forgiveness, a passive emotion, was associated with inhibited motivation and a preference for behaviour maintenance. The impact of these emotions was further linked to the recognition that smoking has negative health consequences, which has been theorized by the TTM as important to the achievement of smoking abstinence. Although critics of the TTM have called for a replacement of this theory with better models, the present study has shown how the incorporation of other, seemingly unrelated theories and constructs can be effective in expanding the TTM to make is a more comprehensive and useful model of the smoking cessation process. 
References

Alvarado, G. F., \& Beslau, N. (2003). Smoking and young people's mental health. Current Opinion in Psychiatry, 18, $397-400$.

Amodei, N., \& Lamb, R. J. (2005). Predictors of initial abstinence in smokers enrolled in a smoking cessation program. Substance Use and Misuse, 40, 141-149.

Amos, A., Wiltshire, S., Haw, S., \& McNeill, A. (2006). Ambivalence and uncertainty: Experiences of and attitudes towards addiction and smoking cessation in the midto-late teens. Health Education Research, 21, 181-191.

Andersen, S. \& Keller, C. (2002). Examination of the transtheoretical model in current smokers. Western Journal of Nursing Research, 24, 282-294.

Aveyard, P., Sherratt, E., Almond, J., Lawrence, T., Lancashire, R., \& Griffin, C. et al. (2001). The change-in-stage and updated smoking status results from a clusterrandomized trial of smoking prevention and cessation using the transtheoretical model among British adolescents. Preventive Medicine, 33(4), 313-324.

Bandura, A. (1997). Self-efficacy: The exercise of control. New York: W.H. Freeman. Bandura, A. (1977). Social Learning Theory. New York: General Learning Press.

Barrett, K. C. (1995). A functionalist approach to shame and guilt. In June Price Tangney \& Kurt W. Fischer (eds.) Self-Conscious Emotions: The Psychology of Shame, Guilt, Embarrassment, and Pride. New York: The Guilford Press.

Benetti-McQuoid, J., \& Bursik, K. (2005). Individual differences in experiences of and responses to guilt and shame: Examining the lenses of gender and gender role. Sex Roles, $53,133-142$. 
Berndsen, M., van der Pligt, J., Doosje, B., \& Manstead, A. S. R. (2004). Guilt and regret: The determining role of interpersonal and intrapersonal harm. Cognition and Emotion, 18, $55-70$.

Brehm J. (1999). The intensity of emotion. Personality and Social Psychology Review, 3, $2-22$.

Brehm, J. W., \& Brummett, B. H. (1998). The emotional control of behaviour. In Gifford Wear \& Kofta Miroslaw (eds.) Personal Control in Action: Cognitive and Motivational Mechanisms. New York: Plenum Press.

Brehm, J. W., Brummett, B. H., \& Harvey, L. (1998) Paradoxical Sadness. Motivation and Emotion, 23, 31 - 44.

Brehm, J. W., \& Self, E. A. (1989). The intensity of motivation. Annual Review of Psychology, 40, $109-131$.

Brown, R. P., \& Phillips, A. (2005). Letting bygones be bygones: further evidence for the validity of the Tendency to Forgive scale. Personality and Individual Differences, $38,627-638$.

Brownson, R. C., Erikson, M. P., Davis, R. M., \& Warner, K. E., (1997). Annual Review of Public Health, 18, $163-185$.

Brundtland, H. (2001). G. Foreword. In J.M. Samet \& S.Y. Yoon (Eds.). Women and the tobacco epidemic - Challenges for the 21st century. Geneva: World Health Organization 
Cunningham, M. R., Steinberg, J., \& Grev, R. (1980). Wanting to and having to help: Separate motivations for positive mood and guilt-induced helping. Journal of Personality and Social Psychology, 38, 181 - 192.

Curry, S., Grothaus, L., \& McBride, M. (1997). Reasons for quitting: Intrisic and extrinsic motivation for smoking cessation in a population-based sample of smokers. Addictive Behaviors, 22, 727 - 739.

Curry, S. J., Marlatt, G. A., Gordon, J., \& Baer, J. S. (1988). A comparison of alternative theoretical approaches to smoking cessation and relapse. Health Psychology, 7, $545-556$

Curry, S., Thompson, B., Sexton, M., \& Omenn, G. S. (1989). Psychosocial predictors of outcome in a worksite smoking cessation program. American Journal of Preventive Medicine, 5, 2-7.

Curry, S., Wagner, E. H., Grothaus, L. C. (1990). Intrisic and extrinsic motivation for smoking cessation. Journal of Consulting and Clinical Psychology, 58, 310-316.

DeBernardo, R. L., Aldinger, C. E., Dawood, O. R., Hansan, R. E., Lee, S. J., \& Rinaldi, S. R., (1999). An e-mail assessment of undergraduates' attitudes towards smoking. Journal of American College Health, 48, 61-66.

DeShea, L., Wohl, M. J. A., \& Wahkinney, R. L. (2005). Looking within: The State SelfForgiveness Scale. Manuscript under review.

De Vries, H., Mudde, A. N., Dijkstra, S., \& Willemsen, M. C. (1998). Differential beliefs, perceived social influences, and self-efficacy expectations among smokers in various motivational phases. Preventive Medicine, 27, 681-689. 
DiClemente, C.C., Prochaska, J.O., Fairhurst, S., Velicer, W.F., Rossi J.S., \& Velasquez, M. (1991). The process of smoking cessation: An analysis of precontemplation, contemplation and contemplation/action. Journal of Consulting and Clinical Psychology, 59, 295-30

Ellison, L. F., Morrison, H. I., de Groh, M., \& Villeneuve, P. J. (1999). Health consequences of smoking among canadian smokers: An update. Chronic diseases in Canada, 20, 36-39

Enright, R. D. (1996). Counseling within the forgiveness triad: On forgiving, receiving, forgiveness and self-forgiveness. Counseling and Values, 40, 107-126.

Etter, J-F. (2004) Associations between smoking prevalence, stages of change, cigarette consumption, and quit attempts across the United States. Preventive Medicine, 38, 369-373.

Exline, J. J., Baumeister, R. F., Bushman, B. J., Campbell, W. K., Finkell, E. J., (2004). Too Proud to let go: Narcissistic entitlemenr ad a barrier to forgiveness. Journal of Personality and Social Psychology, 87, 894-912.

Fava, J., L., Velicer, W. F., \& Prochaska, J. O. (1995). Applying the transtheoretical model to a representative sample of smokers. Addictive Behaviours, 20, 189-203.

Fedewa, B. A., Burns, L. R., \& Gomez, A. A. (2005). Positive and negative perfectionism and the shame/guilt distinction: Adaptive and maladaptive characteristics. Personality and Individual Difference, 38, 1609-1619.

Ferguson \& Stegge, 1998 
Fisher M., \& Exline, J. (2006). Self-forgiveness versus excusing: The roles of remorse, effort, and acceptance of responsibility. Self and Identity, 5, 127-146.

Fitzgerald, T. E., \& Prochaska, J. O., (1989). Nonprocessing profiles in smoking cessation. What keeps people refractory to self-change? Journal of Substance Abuse, 2, 93-111.

Frijda's (1986) Frijda, N. H. (1986). The emotions. Cambridge, UK: Cambridge University Press.

Frijda, N.H., Kuipers, P., and ter Schure, E., 1989. Relations among emotion, appraisal and emotion action readiness. Journal of Personality and Social Psychology. 57, 212-228.

Ghatavi, K., Nicolson, R., MacDonald, C., Osher, S., \& Levitt, A. (2002). Defining guilt in depression: a comparison of subjects with major depression, chronic medical illness and healthy controls, Journal of Affective Disorders, 68, 307-315.

Gilbert, G. .R., Hannan. E. L., Lowe, K. B. (1998). Is smoking stigma clouding the objectivity of employee performance appraisal? Public Personnel Management, $27,285-300$.

Gilovich, T. \& Medvec, V. H. (1995). The experience of regret: What, when, and why. Psychological Review, 102, 379-395.

Grimm, L.G. \& Yarnold, P.R. eds. (1995). Reading and Understanding Multivariate Statistics. Washington D.C.: American Psychological Association 
Grucza R. A., Przybeck T. R., Cloninger C. R. (2005). Personality as a mediator of demographic risk factors for suicide attempts in a community sample. Comprehensive Psychiatry, 46, 214-222.

Hajek, P., \& Belcher, M. (1991). Dream of absent-minded transgression: An empirical study of a cognitive withdrawal symptom. Journal of Abnormal Psychology, 100. $487-491$.

Hall, J. H., \& Fincham, F. D. (2005). Self-forgiveness: The stepchild of forgiveness research. Journal of Social and Clinical Psychology. 24, 621-637.

Health Canada. (2003) Canadian Tobacco Use Monitoring Survey, wave 1. Summary of results. Ottawa: Health Canada.

Herzog, T. A., Abrams, D. B., Emmons, K. M., Linnan, L. A., \& Shadel, W. G. (1999). Do processes of change predict smoking stage movements? A prospective analysis of the transtheoretical model. Health Psychology, 18, 369-375.

Hyland. A., Levy, D. T., Rezaishiraz, H., Hughs, J. R., Bauer, J. E., Giovino, G. A., Cummings, K. M. (2005). Reduction in Amount Smoked Predicts Future Cessation. Psychology of Addictive Behaviours, 19, 221-225.

Hyland, A, Li, Q., Bauer, J. E., Giovino, G. A., Steger, C., \& Cummings, K. M. (2004). Predictors of cessation in a cohort of current and former smokers followed over 13 years. Niccotine and Tobacco Research, 6, 363-369.

Ingersoll-Dayton, B., \& Krause, N. (2005). Self-forgiveness: A component of mental. health in later life. Research on Aging, 27, 267-289 
Kennett, D. J., Morris, E., \& Bangs, A. M. (2006). Learned resourcefulness and smoking cessation revisited. Patient Education and Counseling, 60, 206-211.

Kim, S., \& Shanahan, J. (2003). Stigmatizing smokers: Public sentiment toward cigarette smoking and its relationship to smoking behaviors. Journal of Health Communication, 8, 343-367

Leith, K. P., \& Baumeister, R. F. (1998). Empathy, shame, guilt and narratives of interpersonal conflicts: Guilt-prone people are better at perspective taking. Journal of Personality, 66, 1-37.

Lewis, M. (1992). Self-conscious emotions and the development of self. In Theodore Shapiro \& Robert N. Emde (eds.) Affect: Psychoanalytic Perspectives. Madison, CT: International Universities Press.

Lister, M. and Wohl, M., Rocznik, A., \& Kuiken, D. (2005) The ways we seek forgiveness: A phenomenological study of interpersonal transgressions. New Orleans, LA. Paper presented at the Meeting of the Society for Personality and Social Psychology.

Maltby, J., Macaskill, A., \& Day, L. (2001). Failure to forgive self and others: A replication and extension of the relationship between forgiveness, personality, social desirability and general health. Personality and Individual Differences, 30 , $881-885$.

Matthew, A. G. (2004). Self-Efficacy, Smoking and Smoking Cessation. (Doctoral Dissertation, University of Toronto, 2003). Dissertation Abstracts International, 64(10-B), 5225. 
Mauger, P. A., Perry, J. E., Freeman, T., Grove, D. C., McBride, A. G., \& McKinney, K. E. (1992). Journal of Psychology and Christianity, 11, 170-180.

McCullough, M.E., Worthington, E.L., Jr., \& Rachal, K.C. (1997). Interpersonal forgiving in close relationships. Journal of Personality and Social Psychology,73, 321-336.

McKee, A. A. , O’Malley, S. S., Salovey, P., Krishnan-Sarin, S., Mazure, C. M. (2004). Perceived risks and benefits of smoking cessation: Gender-specific predictors of motivation and treatment outcome. Addictive Behaviours, 30, 423-435.

Meyer, C., \& Waller G. (1999). The impact of emotion upon eating behavior: The role of subliminal visual processing of threat cues. International Journal of Eating Disorders, 25, 319-326.

Miller, D. M., \& Ross, M. (1975). Self serving biases in the attribution of causality: Fact or fiction? Psychological Bulletin, 82, 213-225.

Murphy-Hoefer, R., Alder, S., \& Higbee, C. (2004). Perceptions about cigarette smoking and risks among college students. Nicotine \& Tobacco Research, 6, S371-S374.

Nebot, M., \& Cabezas, C. (1992). Does nurse counseling or offer of nicotine gum improve the effectiveness of physician smoking-cessation advice? Family Practice Research Journal, 12, 263-270.

Neter, J., Kutner, M., Nachtshiem, C., Wasserman, W. (1996) Applied Linear Statistical Models, Chicago: Richard D. Irwin, Inc.

Nichter, M., Nichter, M., Lloyd-Richardson, E. E., Flaherty, B., Carkoglu, A., Taylor, N. (2006). Gendered dimensions of smoking among college students. Journal of 
Adolescent Research, 21, 215-243

Nierkens, V., Stronks, K., van Oel, C. J., \& de Vries, H. (2005). Beliefs of turkish and moroccan immigrants in the netherlands about smoking cessation: Implications for prevention. Health Education Research, 20, 622-634.

O’Hea, E. L., Wood, K. B., \& Brantley, P. J. (2003). The transtheoretical model: Gender differences across three health behaviors. American Journal of Health Behavior, $27,645-656$.

Pearlman, M. Y., Wernicke, R., Thorndike, F., \& Haaga, D. A. F. (2004) Stages of change in smoking cessation: a comparison of expectancies among precontemplators and contemplators. Journal of Rational Emotions \& Cognitive Behaviour Therapy, 22, 131-147.

Prochaska, J. O., \& DiClemente, C. C, (1986). Toward a comprehensive model of change. In William R. Miller \& Nick Heather (eds.) Treating Addictive Behaviors: Processes of Change. New York: Plenum Press.

Prochaska, J. O., \& DiClemente, C. C, (1983). Stages and processes of self-change of smoking: Toward an integrative model of change. Journal of Consulting and Clinical Psychology, 51, 390-395.

Prochaska, J. O., Velicer, W. F., DiClemente, C. C., \& Fava, J, (1988). Measuring the processes of change: Applications to the cessation of smoking. Journal of Consulting and Clinical Psychology, 56, 520-528. 
Prochaska, J. O., Velicer, W. F., Prochaska, J. M., \& Johnson, J. L. (2004). Size, consistency, and stability of stage effects for smoking cessation. Addictive Behaviors, 29, 207-213.

Prochaska, J. O., Velicer, W. F., Redding, C., Rossi, J. S., Goldstein, M., \& DePue, J. et al. (2005). Stage-based expert systems to guide a population of primary care patients to quit smoking, eat healthier, prevent skin cancer, and receive regular mammograms. Preventive Medicine, 41, 406-416.

Quiles, Z. N., Kinnunen, T., \& Bybee, J. (2002). Aspects of guilt and self-reported substance use in adolescence. Journal of Drug Education, 32, 343-362.

Reynoso, J., Susabda, A., Cepeda-Benito, A. (2005). Gender differences in smoking cessation. Journal of Psychopathology and Behavioral Assessment, 27, 227-234.

Rosen, C. S. (2000). Is the sequencing of change processes by stage consistent across health problems? A meta-analysis. Health Psychology, 19, 593-604.

Ross, S. R., Kendall, A. C., Matters, K. G., Worbel, T. A., \& Rye, M. S. (2004). A personological examination of self- and other-forgiveness in the five factor model. Journal of Personality Assessment, 83, 207-214.

Schumann, A., Meyer, C., Rumpf, A. J., Hannover, W., Hapke, U., \& John, U. (2005). Stage of change transitions and processes of change, decisional balance, and selfefficacy in smokers: A transtheoretical model validation using longitudinal data. Psychology of Addictive Behaviors, 19, 3-9. 
Segan, C. J., Borland, R., \& Greenwood, K. M. (2002). Do transtheoretical model measures predict the transition from preparation to action in smoking cessation? Psychology and Health, 17, 417-435.

Segan, C. J., Borland, R., \& Greenwood, K. M. (2004). What is the right thing at the right time? Interaction between stages and processes of change among smokers who make a quit attempt. Health Psychology, 23, 86-93.

Shiv, B., Lowenstein, G., Bechara, G., Damasio, H., \& Damasio, A. R., (2005). Investment Behaviour and the negative side of emotion. Psychological Science, $16,435-439$.

Siahpush, M., Borland, R., \& Scollo, M. (2003). Factors associated with smoking cessation in a national sample of Austrailians. Nicotine \& Tobacco Research, 5, $597-602$.

Silvia, P. J., \& Brehm, J. (2001). Exploring alternative deterrents to emotional intensity: Anticipated happiness, distraction and sadness. Cognition and Emotion, 15, 575592.

Slovic , P. (2000). What does it mean to know a cumulative risk? Adolescents' perceptions of short-term and long-term consequences of smoking. Journal of Behavioral Decision Making, 13, 259 - 266

Statistics Canada. (2003). Canadian Community Health Survey. Retrieved November 17, 2005 from www.statcan.ca/english/freepub/82221XIE/2004002/tables/html 12127_03.htm.

Sutton, S. (2001).Back to the drawing board? A review of applications of the 
transtheoretical model to substance abuse.Addictions, 96, 175-186.

Tabachnick, B. G., \& Fidell, L. S. (2001). Using Multivariate Statistics (4th ed.). Needham Heights, MA: Allyn and Bacon.

Tangney, J.P., Baumeister, R.F., \& Boone, A. (2004). High self-control predicts good adjustment, less pathology, better grades, and interpersonal success. Journal of Personality, 72, 271-324.Tangney, J.P., Boone, A.L., \& Dearing, R. (2005). Forgiving the self: Conceptual issues and empirical findings. In E.L. Worthington, Jr. (Ed.), Handbook of forgiveness, pp. 143-158. New York: Brunner-Routledge. Tangney, J. P., \& Dearing (2002). Shame and Guilt. New York: Guilford Press. Thompson, L. Y., Snyder, C. R., Hoffman, L., Michael, S. T., Rasmussen, H. N., Billings, L. S., Heinze, L., Neufeld, J. E., Shorey, H. S., Roberts, J. C., \& Roberts, D. E. (2005) Dispositional forgiveness of self, others and situations. Journal of Personality, 73, 313-359.

Turner, L. R., \& Mermelstein, R. (2004). Motivation and reasons to quit: Preventative validity among adolescent smokers. American Journal of Health Behavior, 28, $542-550$.

Velicer, W.F., DiClemente. C. C., Prochaska, J.O., \& Brandenberg, N. (1985). Decisional balance measure for assessing and predicting smoking status. Journal of Personality and Social Psychology, 48, 1279-1289.

Velicer, W.F., DiClemente, C.C., Rossi, J.S., \& Prochaska, J.O. (1990). Relapse situations and self-efficacy: An integrative model. Addictive Behaviors, 15, 271283. 
Velicer, W.F., Fava, J.L., Prochaska, J.O., Abrams, D.B., Emmons, K.M., \& Pierce, J. (1995). Distribution of smokers by stage in three representative samples. Preventive Medicine, 24,401-411.

Velicer, W. F., Hughes, S. L., Fava, J., L., \& Prochaska, J. O. (1995). An empirical typology of subjects within stage of change. Addictive Behaviours, 20, 299-320.

Walster, E., Berscheid, E. \& Walster, G.W. (1973). New directions in equity research. Journal of Personality and Social Psychology, 25, 151-176.

Walter, J. 1., \& Burnaford, S. M. (2006). Developmental changes in adolescents' guilt and shame: The role of family climate and gender. North American Journal of Psychology, 8, $321-338$.

Ward, R. M., Velicer, W. F., Rossi, J. S., Fava, J. L., \& Prochaska, J. O. (2004). Factorial invariance and internal consistency for the decisional balance inventory--short form. Addictive Behaviors, 29, 953-958.

Weinstein, N. D., Slovic, P., \& Gibson, G. (2003). Accuracy and optimism in smoker's related beliefs about quitting. Nicotine \& Tobacco Research, 6, S375-S380.

West, R. (2005) Time for a change: putting the Transtheoretical (Stages of Change) Model to rest. Addiction, 100, 1036-1039.

Wetter, D. W, Kenford, S. L., Smith, S. S,, Fiore, M. C., Jorenby, D. E, Baker, T. B. (2004) Journal of Consulting and Clinical Psychology, 1999, Vol. 67, No. 4, 555562.

Witvliet, C.V. O., Ludwig, T. E. \& Vander Laan, K. L. (2001). Granting forgiveness or harboring grudges: Implications for emotion, physiology, and health. 
Psychological Science, 121, 117-123.

Worthington, E.L., Jr., \& Scherer, M. (2004). Forgiveness is an emotion-focused coping strategy that can reduce health risks and promote health resilience: Theory, review, and hypotheses. Psychology and Health, 19, 385-405.

Wright, R. A. (1996). Brehm's theory of motivation as a model of effort and cardiovascular response. In Peter M. Gollwitzer \& John A. Bargh (eds.) The Psychology of Action: Linking Cognition and Motivation to Behavior. New York: Guilford Press.

Wright, R. A., Contrada, R. J., \& Patane, M. J. (1986). Task difficulty, cardiovascular response, and the magnitude of goal valence. Journal of Personality and Social Psychology, 51, 837-843. 


\section{APPENDDIX A}

Measures

\section{Background Questionnaire}

Please answer the following questions about yourself.

1. ID:

2. Age:

3. Sex: Female Male

4. First Language English French Other

5. Ethnic Background:

\section{Smoking Stages of Change}

We would like to know about your current smoking behaviour as well as your desire to quit smoking. Please select the response that best describes your current situation.

Are you currently a smoker? (please check one)

Yes, I currently smoke

- No, I quit within the last 6 months

No, I quit more than 6 months ago

No, I have never smoked

In the last year, how many times have you quit smoking for at least 24 hours?

On average, how many cigarettes do you smoke each day?

Are you seriously thinking of quitting smoking? (please check one)

Yes, within the next 30 days

ㄱes, within the next 6 months

No, not thinking of quitting 
Percieved Difficulty of Quitting Smoking

How easy would it be for you to quit and never smoke again?

$\square$ Easy, and I can do can do it without much trouble

Hard, but I could do it if I really tried

$\square$ Very hard, and I might not be able to do it

If you decided to quit smoking, how sure are you that you will be successful?

$\square$ Very sure, I would be successful

- Somewhat sure, I may or may not be successful

$\square$ Very unsure, I don't think that I would be successful

Do you feel you would have the ability to quit smoking if you wanted to?

- Yes, I know I have the ability to quit smoking

I I am unsure about my ability to quit smoking

$\square$ I seriously doubt my ability to quit smoking

Perception of Smoking as a Transgression

Smoking causes serious health problems

YES NO

Whenever possible, people should not smoke

YES NO 
State Shame and Guilt Scale

The following are some statements that may or may not describe how you are feeling right now about your current or past smoking. Please rate each statement using the 5point scale below. Remember to rate each statement based on how you are feeling about your current or past smoking right at this moment.

1

Not feeling this

2 way at all

When I think of my smoking, I

feel good about myself.

want to sink into the floor and disappear.

feel remorse, regret.

feel worthwhile, valuable.

feel small.

feel tension about my smoking.

feel capable, useful

feel like I am a bad person.

cannot stop thinking about my smoking.

feel proud

feel humiliated, disgraced.

feel like apologising, confessing

feel pleased about my smoking

feel worthless, powerless.

feel bad about my smoking
3

Feeling this way somewhat
5

Feeling this way very strongly 
Offense-Specific Forgiveness Measure (Modified)

Please read each statement carefully and consider how well it applies to your current or past smoking. On the seven-point scale below each item, circle one number to indicate your reaction.

I forgive myself for smoking.

I feel angry towards myself for my smoking behaviour.

Even though my smoking may hurt me, I do not feel ill will towards myself.

I dislike myself for my smoking behaviour.

When thinking about my smoking behaviour I feel warmly towards myself.

I criticise myself because of my smoking.

I put myself down because of my smoking.

I give myself some slack for smoking
Strongly Strongly

Agree

$\begin{array}{lllllll}1 & 2 & 3 & 4 & 5 & 6 & 7\end{array}$

1223345667

$\begin{array}{lllllll}1 & 2 & 3 & 4 & 5 & 6 & 7\end{array}$

$\begin{array}{lllllll}1 & 2 & 3 & 4 & 5 & 6 & 7\end{array}$

$\begin{array}{lllllll}1 & 2 & 3 & 4 & 5 & 6 & 7\end{array}$

$\begin{array}{lllllll}1 & 2 & 3 & 4 & 5 & 6 & 7\end{array}$

$\begin{array}{lllllll}1 & 2 & 3 & 4 & 5 & 6 & 7\end{array}$

$\begin{array}{lllllll}1 & 2 & 3 & 4 & 5 & 6 & 7\end{array}$

Disagree

\section{Smoking Decisional Balance (Short Form)}

The following statements represent different opinions about smoking. Please rate HOW IMPORTANT each statement is to your decision to smoke according to the following five-point scale.

$$
\begin{gathered}
1=\text { Not important } \\
2=\text { Slightly important } \\
3=\text { Moderately important } \\
4=\text { Very important } \\
5=\text { Extremely important }
\end{gathered}
$$

1. Smoking cigarettes relieves tension.

2. I'm embarrassed to have to smoke.

3. Smoking helps me concentrate and do better work.

4. My cigarette smoking bothers other people.

5. I am relaxed and therefore more pleasant when smoking.

6. People think I'm foolish for ignoring the warnings about cigarette smoking. 
Listed below are situations that lead some people to smoke. We would like to know HOW TEMPTED you may be to smoke in each situation. Please answer the following questions using the following five-point scale.

$$
\begin{gathered}
1=\text { Not at all tempted } \\
2=\text { Not very tempted } \\
3=\text { Moderately tempted } \\
4=\text { Very tempted } \\
5=\text { Extremely tempted }
\end{gathered}
$$

1. With friends at a party.

2. When I first get up in the morning.

3. When I am very anxious and stressed.

4. Over coffee while talking and relaxing.

5. When I feel I need a lift.

6. When I am very angry about something or someone.

7. With my spouse or close friend who is smoking.

8. When I realize I haven't smoked for a while.

9. When things are not going my way and I am frustrated. 
Smoking Processes of Change (Short Form)

The following experiences can affect the smoking habits of some people. Think of any similar experiences you may be currently having or have had in the last month. Then rate the FREQUENCY of this event on the following five-point scale.

$$
\begin{gathered}
1=\text { Never } \\
2=\text { Seldom } \\
3=\text { Occasionally } \\
4=\text { Often } \\
5=\text { Repeatedly }
\end{gathered}
$$

1. When I am tempted to smoke I think about something else.

2. I tell myself I can quit if I want to.

3. I notice that non-smokers are asserting their rights.

4. I recall information people have given me on the benefits of quitting smoking.

5. I can expect to be rewarded by others if I don't smoke.

6. I stop to think that smoking is polluting the environment.

7. Warnings about the health hazards of smoking move me emotionally.

8. I get upset when I think about my smoking.

9. I remove things from my home or place of work that remind me of smoking.

10. I have someone who listens when I need to talk about my smoking.

11. I think about information from articles and ads about how to stop smoking.

12. I consider the view that smoking can be harmful to the environment.

13. I tell myself that if I try hard enough I can keep from smoking.

14. I find society changing in ways that makes it easier for non-smokers.

15. My need for cigarettes makes me feel disappointed in myself.

16. I have someone I can count on when I'm having problems with smoking.

17. I do something else instead of smoking when I need to relax.

18. I react emotionally to warnings about smoking cigarettes.

19. I keep things around my home or place of work that remind me not to smoke

20. I am rewarded by others if I don't smoke 
APPENDIX B

\section{Informed Consent Form}

The purpose of an informed consent is to insure that you understand the purpose of the study and the nature of your involvement. The informed consent must provide sufficient information such that you have the opportunity to determine whether you wish to participate in the study.

Study Title: Carleton University Smoking Study

Research Personnel:

mwohl@connect.carleton.ca

Dr. Michael Wohl, Tel. 520.2600 ext. 2908; EMAlL:

Andrea Thompson Tel. 520.2600 ext. 6312; EMAIL: andy.thomps@gmail.com

Celina Boule-Perroni Tel. 520.2600 ext. 6312; EMAIL: c.boule.perroni@gmail.com

If you have any ethical concerns about how this study please contact Dr. J. Mantler (Chair of the Carleton University Ethics Committee for Psychological Research , 5202600, ext. 4173) or Dr. M. Gick (Chair of the Department of Psychology at Carleton University, 520-2600, ext. 2648).

Purpose and Task requirements: The aim of the present study is to understand smoking behaviour in young adults. We will be asking you to complete a questionnaire assessing your smoking behaviour and attitudes as well as some other measures. The time to complete the questionnaire will be approximately $30 \mathrm{~min}$. This session is part of a larger study on smoking behaviour. As such, we will ask for your consent to contact you for one additional follow-up session to be conducted throughout the school year. This follow-up session involves completing a questionnaire package that will ask you questions about your smoking, desire to quit, mood as well as other measures.

Potential risk/discomfort. Some people can become stressed when thinking about their smoking behaviour.

Right to withdraw and Anonymity/confidentiality. Your participation in this study is entirely voluntary. At any point during the study you have the right to not complete certain questions or to withdraw with no penalty whatsoever. The data collected in this experiment are confidential as will your contact information should you choose to provide it on the next page. That is, the data and contact information will be available only to the researchers associated with this project. 
Compensation: Participants will be provided with compensation at each session attend. Participants enrolled in introductory psychology will receive a credit towards their final grade. Participants not enrolled in introductory psychology will receive a $\$ 2$ gift certificate to Tim Horton's.

I have read the above description of the study entitled "Carleton University Smoking Study" The data collected will be used in research publications and/or for teaching purposes. My signature indicates that I agree to participate in the study, and this in no way constitutes a waiver of my rights.

Full Name (please print):

Participant Signature:

Date:

Researcher Signature:

Date: 
APPENDIX C

\author{
Debriefing
}

This post-survey information is designed to help you understand the nature of the research. We are conducting studies examining young adults' smoking behaviour and attitudes. Thus, the questionnaires that you just completed will help us determine how much first year students at Carleton University smoke, the factors that influence decisions to quit smoking and whether or not such decisions actually result in successful quit attempts.

We would like to thank you for participating in this research. Your time and efforts are greatly appreciated! Without the participation of people like you important questions in psychology could not be answered.

If you would like more information on smoking and how to quit we encourage you to contact Carleton Health Services at 520-6674. You may also wish to contact the Smoker's Helpline, a free and confidential telephone service provided by the Canadian Cancer Society at (toll free) 1-877-513-5333.

If you have any questions or comments about this research, then please feel free to contact Andrea Thompson (520.2600 ext. 6312; andy.thomps@ gmail.com), or Dr. Michael Wohl (520.2600 ext. 2908; mwohl@connect.carleton.ca)

If you have any ethical concerns about how this study please contact Dr. J. Mantler (Chair of the Carleton University Ethics Committee for Psychological Research, 5202600, ext. 4173) or Dr. M. Gick (Chair of the Department of Psychology at Carleton University, 520-2600, ext. 2648).

If you have any personal concerns about your emotionality, or general physical or emotional well-being that you would like to discuss with somebody, you might wish to contact the Health and Counselling Services at 520-6674. 
The questionnaire you have just completed is part of a larger study on smoking cessation. As such, we would like to have your permission to contact you at a later date so that you may take part in the next part of this study. By agreeing to be contacted you are not obligated to participate, as your participation is always voluntary. Also, if you choose to not be contacted you will not be treated any differently.

We appreciate your consideration look forward to seeing you again!

By filling out this form and signing my name I give the researcher permission to call me at the number I have provided below. I understand that this does not guarantee my participation in any further studies, as my participation is always voluntary.

Name

Signature

Phone Number

Primary email address 


\section{APPENDIX E}

\section{Preliminary Analyses}

\section{Outliers}

Frequency distributions were conducted on the standardized scores of each of the variables of interest.. One outlier greater than three standard deviations from the mean were found for the reevaluation, behavioural and management subscales of the Processes of Change measure. These outliers (which ranged from 3.04 to 3.09 standard deviations from the mean) were deemed to be not sufficiently large enough to affect the results of any tests, and so were retained to preserve data accuracy ${ }^{1}$. Outliers on the set of predictors used to assess hypothesis one (i.e., guilt, self-forgiveness and perceived difficulty) were evaluated using centred leverage values. Since the identification of gender differences in the key variables of interest necessitated separate regression models for men and women, leverage values were calculated for men and women separately. The critical leverage value for men was found to be $.14(3 \mathrm{p} / \mathrm{n}=3(3) / 63)$. This values was exceed for four male participants. Further examination of Cook's Distance revealed that these cases were not influential (i.e., all values < 1). Analyses of the obtained DFFITS and DFBETAS also indicated that both the predicted values of the outcome variable and the beta weights of the predictors were not influenced by these outliers. Of the women participants, the critical leverage value was found to be $0.74(3 \mathrm{p} / \mathrm{n}=3(3) / 121)$. Six female cases, exceeded this values, however, as was found for the men, analysis of Cook's Distance, DFFITS and DFBETAS revealed these outliers to be uninfluential.

\footnotetext{
${ }^{1}$ Analyes conducted with scored adjusted to be within three standard deviations did not change the direction of significance for any test.
} 


\section{Treatment of Missing Data}

Analysis of missing responses was conducted on the sample which revealed that missing data accounted for less than ten percent of the entire data set and no more than nine percent of the data for any one participant. All participants had at least partial data for every subscale, and so missing responses on all quantitative items were replaced with the item mean. All subscales were then computed using the new, more complete data set. Three participants did not respond to the qualitative item regarding intent to quit. Since this item was unable to be replaced, these participants were excluded from any analysis that included stage of change.

\section{Effects of Questionnaire Setting}

Chi square tests were conducted to test for setting effects on the qualitative variables of Stage and gender. Results of this analysis revealed that both questionnaire settings yielded no differences in Stage or gender proportions. Independent samples ttests were conducted to test for the differences in the quantitative variables of interest based on the questionnaire setting (completed in a campus computer lab versus completed at a place of participant's choosing). Results revealed there to be no significant differences in any of key variables, differences were observed for several of the Processes of Change subscales. Specifically, participants who completed the questionnaire in the computer lab setting reported lower levels of the management processes, $t(182)=-3.71$, $p<.001$. It is likely that many of the non-laboratory setting participants completed the questionnaire in their home, where they had more control over placement of reminders 
not to smoke as well as the removal of smoking cues (the two behaviours assessed by this subscale). If this is the case then the management processes would have been far more salient that it was for the participants who completed the questionnaire in an environment that they had no control over. Thus, the scores obtained through the computer lab setting are likely to be under representative of actual behaviour. If this is the case, management scores for the computer lab participants would be invalid and should be removed from further analysis. To control for the effect of these invalid scores, analyses were conducted with and without them. However, removal of management scores obtained in the computer lab setting did not change the direction of significance for any test. Therefore, these scores were retained.

\section{Consent to be contacted differences}

Nine participants did not give their consent to be contacted to participate in the follow-up assessment. Several independent t-tests were conducted to ensure that participants who withheld consent occurred at random. All tests involving the key variables of Guilt, Self-forgiveness, and perceived difficulty were not significant. Individuals who did not agreed to be consented did report significantly lower levels of temptation in positive affective and social situations and habitual situations, $t(184)=$ $3.13, p<.01$

\section{Attrition Effects}

Several independent samples t-tests were conducted to analyse differences on the qualitative variables. No significant differences were observed for any of the variables of interest. To assess possible differences in gender and stage of change proportions, chi 
square tests were conducted. Again, no differences in were observed. Thus, it can be assumed that participants who completed the follow-up assessment consisted of a random sample of all participants.

Regression Assumptions

Before beginning the regression analysis that was used to test hypothesis one, the assumptions of independence, normality and homoscedasticity (Neter, et al., 1996) were assessed. Participants who completed the measures in the computer lab setting did so under supervision of the researcher at individual computers. Therefore, the assumption of independence can be assumed to be met. There is also no reason to believe that participant who completed the measures outside of the supervised setting did not do so independently.

Plots of observed and predicted cumulative frequencies revealed the scores to be normally distributed. Predicted values were also plotted against standardized residuals to assess departures from linearity and ensure that the error variances were constant. The coefficient of correlation between the standardized residuals and the predicted values was $.000, \mathrm{p}=1.00$, indicating that these assumptions were met.

\section{Logistic Regression Assumptions}

Given the inclusion of three continuous predictors in the multinomial logistic regression model, it was not surprising to find that classification of the observed and predicted frequencies revealed that approximately $66 \%$ of the cells had zero frequencies. This invalidated the usual Pearson and Deviance goodness-of-fit tests that assume all case frequencies are $>1$. However, when observed frequencies are low, an alternative 
goodness-of-fit test may be obtained through the chi-square statistic reported in the "Model Fitting Information" table given in SPSS (Tabachnick \& Fidell, 2001). In the present study, $\chi^{2}=84.53, p<.001$, indicating that the null hypothesis that all effects of the independent variable are zero can be rejected.

Although the logistic regression model is robust against departures from normality and homoscedasticity, it is can be severely affected by the presence of outliers and multicollinearity. The assumption of no outliers had been previously addressed and was deemed to be met. Multicollinearity among the predictors was first investigated by observing the pairwise correlations among the predictor variables. Significant coefficients of correlation were found for all predictors. Variance inflation factors for the predictors were found to be well below the recommended critical value of 10 (Myers, 1990, as cited in Stevens, 2002). Logistic regression analysis also requires discrete outcome categories. This assumption was met, as the staging model used to create the categories was exhaustive and only current smokers were included in the sample. 